NBER WORKING PAPER SERIES

\title{
DIVERSITY IN INNOVATION
}

Paul A. Gompers

Sophie Q. Wang

Working Paper 23082

http://www.nber.org/papers/w23082

\author{
NATIONAL BUREAU OF ECONOMIC RESEARCH \\ 1050 Massachusetts Avenue \\ Cambridge, MA 02138 \\ January 2017
}

Support for this research was provided by the Division of Research at the Harvard Business School. Lauren Cohen provided helpful comments and suggestions. Kevin Huang provided excellent research assistance. Paul Gompers has invested in and consulted for venture capital firms. The views expressed herein are those of the authors and do not necessarily reflect the views of the National Bureau of Economic Research.

NBER working papers are circulated for discussion and comment purposes. They have not been peer-reviewed or been subject to the review by the NBER Board of Directors that accompanies official NBER publications.

(C) 2017 by Paul A. Gompers and Sophie Q. Wang. All rights reserved. Short sections of text, not to exceed two paragraphs, may be quoted without explicit permission provided that full credit, including ( $)$ notice, is given to the source. 
Diversity in Innovation

Paul A. Gompers and Sophie Q. Wang

NBER Working Paper No. 23082

January 2017

JEL No. G2,G24,G3,J01,J11,J16,J24,J7,O15,O3

\begin{abstract}
$\underline{\text { ABSTRACT }}$
In this paper we document the patterns of labor market participation by women and ethnic minorities in venture capital firms and as founders of venture capital-backed startups. We show that from 1990-2016 women have been less than 10\% of the entrepreneurial and venture capital labor pool, Hispanics have been around 2\%, and African Americans have been less than $1 \%$. This is despite the fact that all three groups have much higher representation in education programs that lead to careers in these sectors as well as having higher representation in other highly-compensated professions. Asians, on the other hand, have much higher representation in the venture capital and entrepreneurial sector than their overall percentages in the labor force. We explore potential supply side explanations including both education attainment as well as relevant prior job experience. We also explore the correlation between diversity and state-level variations. Finally, we discuss how these patterns are consistent with homophily-based hiring and homophily-induced information flows about career choices. We end the paper by discussing areas for future research.
\end{abstract}

\author{
Paul A. Gompers \\ Harvard Business School \\ Baker Library 263 \\ Soldiers Field \\ Boston, MA 02163 \\ and NBER \\ pgompers@hbs.edu \\ Sophie Q. Wang \\ Department of Economics \\ Harvard University \\ Littauer Center \\ 1805 Cambridge Street \\ Cambridge, MA 02138DRESS HERE \\ sophieqzwang@gmail.com
}

A online appendix is available at http://www.nber.org/data-appendix/w23082 
1 INTRODUCTION 3

2 DATA CONSTRUCTION 3

3 GENDER AND ETHNICITY TRENDS FOR ENTREPRENEURS AND VCS 4

3.1 Summary Statistics 4

3.2 Time Series Trends $\quad 5$

3.2.1 Gender Trends 6

3.2.2 Ethnicity Trends 6

3.2.3 Gender and Ethnicity Interactions 7

3.3 Industry Patterns $\quad 8$

3.3.1 Gender Patterns 8

3.3.2 Ethnicity Patterns 9

4 POTENTIAL EXPLANATIONS 10

4.1 Potential Supply-Side Explanations $\quad 10$

4.1.1 Overview of Education and Employment Statistics 10

4.1.2 Additional Data Descriptions 12

4.1.3 Gender Trends 12

4.1.3.1 The Case for Women Entrepreneurs 12

4.1.3.2 The Case for Women Venture Capitalists 13

$\begin{array}{lll}\text { 4.1.4 Ethnicity Trends } & 14\end{array}$

4.1.4.1 The Case for Minority Entrepreneurs $\quad 14$

4.1.4.2 The Case for Minority Venture Capitalists 15

4.2 Potential Social and Cultural Explanations 17

4.2.1 Overview of State-Level Variations 17

$\begin{array}{lll}\text { 4.2.2 Variations of State Level Characteristics } & 18\end{array}$

4.2.2.1 Political Leanings 18

4.2.2.2 Unionization Rates 19

4.2.2.3 Religious Affiliations 20

4.2.2.4 GDP Per Capita 20

4.2.2.5 Improvements in Education $\quad 21$

4.2.2.6 Parental Benefits 21

5 DISCUSSION OF POTENTIAL MODELS AND CAUSAL INFERENCE 22

6 CONCLUSION 25 


\section{Introduction}

Two of the most striking patterns in labor economics in the past half-century have been the increase in female labor market participation along with the growing ethnic diversity of the American workforce. Given the rising rate of labor participation among females in all parts of the world, there has not been a larger factor affecting global labor supply and demand dynamics. As an example of the magnitude, female labor market participation in the US has nearly doubled from 1950, going from 33\% to 57\% in $2016 .{ }^{1}$ Further, the overall US increase has been shared broadly across fields in the economy, including the professional fields of law, medicine, and business. Similarly, the growth in Asian, African American, and Hispanic populations in the US has led to dramatic increases in the diversity of the labor pool.

In this survey we document a sharply contrasting phenomenon in the innovation sector which we identify as both young entrepreneurial firms (idea generation), and the venture capital industry (capital provision). After carefully documenting these contrasting trends in innovation, we examine both supply and demand factors that could help explain the substantial underrepresentation of woman, African American, and Hispanics. Finally, we end by discussing potential areas for future research in this area. Our goal is two-fold. First, we seek to shed light on the facts. What have been the dynamics of participation for women and minorities over the past twenty five years in the venture capital and entrepreneurial sectors? Second, we hope to offer some potential hypotheses for the patterns we see. Our goal is not to provide definitive explanations for the patterns. Rather we hope our results can provide the foundation for meaningful research on these important questions.

We motivate our analysis by examining patterns of female and minority participation in the venture capital and entrepreneurial markets over time. Additionally, we compare these patterns to the participation rates in other highly-compensated professions. The time series patterns and cross sectional comparisons for each group motivate our search for potential explanations for the different experience of women and minorities in the innovation sector.

1 United States Bureau of Labor Statistics (2016) http://www.bls.gov/opub/ted/2000/feb/wk3/art03.htm , https://fred.stlouisfed.org/series/LNS11300002). 
Figure 1 shows the evolution of female labor market participation in professional industries in the US along with total US female labor market participation. The figure shows our estimate of the relative fraction of each category entering the labor force or a particular profession who are female. We think looking at flow variables is more relevant to changing participation barriers because the current stock of labor within a profession represents the historical experience with past barriers to entry. As can be clearly seen, total female labor market participation has stayed roughly constant over the 25 years since the early 1990s: roughly 45$46 \%$ of the total US labor force was female. Moreover, while the professional fields of medicine and law started the period well below economy-wide levels of female participation (dark and light violet dashed lines, respectively), they both saw a marked increase through the present day. In fact, not only have they fully converged, but at present both stand slightly above the economy-wide rate of $46.78 \%$; $49.84 \%$ for medicine and $50.84 \%$ for law. From starting points of just $26.58 \%$ (for medicine) and $35.52 \%$ (for law) in the early 1990s, these increases represent substantial shifts in terms of economic magnitude in such a short period of time. Figure 1 also shows the evolution of female entry into the innovation sector over this time period, showing in solid blue entrepreneurs and in red venture capital. In stark contrast to other professional fields, women in the innovation sector both began the early 1990s at much lower levels, and did not show nearly the same convergence tendency - ending the period at roughly the same $10 \%$ levels. We will explore, document, and dissect this empirical fact in greater detail throughout the paper, but it is worth noting that these trends are occurring over a time period during which, by most metrics, "innovation activity" became a more central part of the US economy (e.g., employment and wages in the innovation economy have grown at a much faster rate than the overall economy). Similarly, research has shown that the venture capital and entrepreneurial sectors are responsible for large wealth accumulation and job creation given their rapid growth. Finally, in many top business schools, jobs in the venture capital and entrepreneurial sector are among the most highly sought positions.

One potential argument might be that the finance- and business-related sectors have seen this same lack of female participation growth. Figure 2 explores this hypothesis, comparing innovation sectors to the two largest finance and business-related professions produced in business school over this time period: 
consulting and investment banking. Figure 2 looks at how the female participation entry rates in venture capital and entrepreneurship from 2010-2015 compare to women's entry rates into consulting and investment banking. The lower level of female labor market participation does not appear in other finance-related professions: consulting and investment banking have three to four times the female participation rates as innovation, and much closer to economy-wide levels

Figures 3 and 4 explore the same patterns in the African American population. Figure 3 shows the African American labor market entry participation has increased from about $11 \%$ in 1990 to $12 \%$ in 20102015. The share of undergraduate degrees being granted to African Americans students increased by more than $50 \%$, from $6 \%$ of BAs granted in 1990 to $9.2 \%$ in 2010-2015. The pattern of African American entry into the legal and medical professions has not changed dramatically over the 25 year period, remaining around $5 \%$ in each profession. Similarly, the rate of African American participation in venture capital and entrepreneurial sectors has not grown either. Strikingly, however, the rate is substantially lower than their participation in law or medicine, always less than $1 \%$.

Figure 4 compares the African American entry participation rates for venture capital and entrepreneurship to consulting and investment banking for the most recent five year period, 2010-2015. Figure 4 shows that the entrepreneurial and venture capital entry rates for African Americans $(0.83 \%$ and $0.67 \%$ respectively) are an order of magnitude lower than their participation in entry to consulting and investment banking (8.8\% and 6.09\% respectively.) Consulting and investment banking participation rates are also much closer to those economy-wide. Overall, the results suggest that in other business-related fields, African Americans have increased in representation dramatically, while their fraction of the innovation sector has remained small.

The time-series for Asian labor market participation is shown in Figures 5 and 6. The pattern for Asians is quite different than from women and African Americans. Asians increased slightly as a fraction of total US labor market entrants rising from 4\% in 1990 to roughly 5\% in 2010-2015. The fraction of all BA degrees granted is roughly in line with entry into the labor force. The striking pattern, however, is the large increase in entry rates to all professional-degree sectors we tabulate. As a fraction of physicians entering the 
labor force, Asians grew from 10\% in 1990 to nearly 30\% in 2010-2015. While not as dramatic, Asian labormarket participation in the venture capital and entrepreneurial sectors also rose dramatically. Among new venture capitalists and entrepreneurs entering the market, Asians grew from $10 \%$ and $5 \%$ to $18 \%$ and $15 \%$, respectively.

The Asian labor-market participation in other finance related field has been similarly high. From 2010-2015 Asians represented 18\% of new entrepreneurs and 15\% of new venture capitalists while they were $16.9 \%$ of new consultants and $24.8 \%$ of new investment bankers. These levels are three to four times the overall labor market entry rates for Asian Americans. The overall pattern of these summaries indicates that Asians started the period over-represented in the innovation sector relative to their labor market participation rates and increased substantially from that level.

Finally, we examine the experience of Hispanics in Figures 7 and 8. Hispanics have witnessed the fastest increase in entry to the labor force, rising from 9\% of total US labor market entrants in 1990 to nearly $16 \%$ in 2010-2015. Likewise, the fraction of BAs granted to Hispanic students has also more than doubled, from $4.2 \%$ in 1990 to $9.5 \%$ in $2010-2015$. The relative evolution in professional-degree sectors, however, shows a slightly divergent pattern from the prior three groups. Hispanic entrepreneurs and venture capitals have increased markedly, from about $1 \%$ each in 1990 to nearly $5 \%$ of new entrepreneurs and $3.2 \%$ of new venture capitalists in 2010-2015. These rates and increases are much higher than for Hispanic doctors and lawyers.

If we look at the most recent five year period, we see that Hispanic venture capital market entry and entry into the entrepreneurial sector are roughly comparable to Hispanic entry rates into consulting and investment banking. These rates are, however, still three to five times lower than Hispanics overall percentages of labor market entry. So while the entry rates have improved, they still represent an overall lack of Hispanic representation in the innovation sector.

More broadly, in this survey we establish eight main empirical facts: 
I.) The empirical regularity of a low level of female, African American, and Hispanic labor market participation in the innovation sector along with a high and growing participation of Asians as both entrepreneurs and the venture capitalists that fund them.

II.) When the fraction of the entrepreneurial pool (i.e., educational, training, and work-experience typical in this sector) for women, African Americans, and Hispanics is compared to the observed venture capital and founder participation of these groups, each group has meaningfully and persistently lower representation than would seem appropriate given their proportions of those with requisite backgrounds to enter the sectors.

III.) The time-series evolution and the cross-sectional (e.g., cross-industry) dynamics of this phenomenon show no increase for female or African American entry into the innovation sector and large relative increases of both Asians and Hispanics.

IV.) This same pattern is not present for women across similar fields in terms of required training (e.g., medicine and law that require additional, professional masters human capital accumulation) for which women dramatically increased their entry while Hispanics and African Americans saw no increases in these sectors.

V.) This same pattern is absent for women and African Americans in otherwise equivalent financeand business-related jobs (with, on-average, nearly identical past experience profiles) such as investment banking or consulting where they are represented in much higher percentages.

VI.) This empirical fact is not driven by adequately trained women or African Americans (MBAs and science related advanced degrees have been increasing over the sample for both groups, and there has been a relatively sizable pool of technical and MBA-trained women in the underlying age-cohorts).

VII.) We document and explore the geographic concentration of this phenomenon, along with parallel trends in ethnicities within the innovation space.

VIII.) We document and explore the powerful school-based networks and prior work-based networks out from which innovators and venture capitalists are borne. 
We end by discussing the potential explanations for the underrepresentation of female, African American, and Hispanic labor market participation in the innovation space (and its unique features) over time through the present-day. We consider which of these explanations are most consistent with the empirical facts we observe. In particular, what portion of the dynamics we observe appear driven by optimal labor supply-side choices (e.g., actively deciding not to go into VC for utility maximizing reasons), and which might be more subject to demand-side explanations (e.g., search frictions caused by homophily in which agents only engage close acquaintances to begin ventures or join small VC teams, tending to associate with others of the same gender or ethnicity).

The survey is of broad interest to four distinct sets of researchers. First, any researcher in innovation and entrepreneurship interested in human capital supply and demand may find the analysis helpful. Second, labor economists that study similarly disparate labor market outcomes in their sub-field may take away something instructive from the dynamics we document. Third, given the equilibrium organizational structure of firms in both venture capital and early entrepreneurial ventures, those interested in organizational behavior and social psychology manifested in the small group setting - importantly with large, steep incentivize compensation payoffs in an actual field setting - may find this an interesting laboratory to explore. Lastly, any policy maker or academic interested in the causes and consequences of gender and ethnicity gaps in labor market participation will find the survey an important source for "facts" about a key labor-force segment from which to structure further study.

The remainder of the survey is organized as follows: Section 2 describes how we construct the dataset for entrepreneurs and venture capitalists. Section 3 describes the time-series trends and industry patterns along the dimensions of gender and ethnicity. Section 4 explores possible explanations. It presents statistics based on the supply side factors: namely, education and prior work experience. It also explores social and cultural factors based on state-level variations. Section 5 discusses economic models consistent with the empirical patterns observed in the data. Section 6 concludes. 


\section{Data Construction}

The core data used in this paper are derived from several different sources. We start with VentureSource, a database that contains detailed information on venture capital investments. Our data cover the period from 1990 through mid-2016. We start our analysis in 1990 because the data become reasonably comprehensive at that point in time. For each portfolio company, we have the identities of the individuals involved with the firm including founders, venture capital investors, angel investors, board members, and early hires. We focus on the portfolio company founders as well as the venture capitalists on the board of directors. Throughout the paper, we will refer to company founders as "entrepreneurs". In addition to information about the people involved in the company, we also have information on the portfolio company's location and industry. A founder enters the data in the year in which they receive their first round of financing. ${ }^{2}$ A venture capitalist enters the data in the year they make their first investment for which they sit on the board of directors.

For each individual entrepreneur and venture capitalist in the dataset, we collect a broad range of biographical information such as gender, ethnicity, education, and prior job experience. We collect this information from a variety of sources, including a leading online resume website, web searches, SEC filings and news articles. The education information includes the academic institution attended along with the specific type of degree granted. Degree types include undergraduate, postgraduate non-business (Ph.D., M.S., J.D., and M.D.), and postgraduate business (MBA). For prior job experience, we record the company names as well as job titles.

Entrepreneur and venture capitalist genders are primarily determined based on first names. In the cases of unisex names, we determine gender by reading news articles and web pages mentioning or containing pictures of the individual. To identify ethnicity, we use the name-matching algorithm developed by Kerr and Lincoln (2010) to determine the most likely ethnicity based on their first and last names. Due to the ambiguity in identifying African Americans names, anyone who was classified as White is then searched on the Internet

\footnotetext{
${ }^{2}$ We do not have information on founding dates, hence, we time entry as the time of first funding.
} 
for photos based upon the full name, the company name and the company location. The African American designation is then based upon review of the photos. Individual entrepreneurs and venture capitalists are classified into six non-overlapping ethnic groups: White, East Asian, Indian, Hispanic, African American, and all others. In this paper, we group East Asian and Indian as Asian. Our overall match rates for both gender and ethnicity exceed $99 \% .^{3}$

In this paper, we choose to focus on entrepreneurs that have received venture financing. Although this by no means captures the full spectrum of entrepreneurs, venture financing remains an important source of entrepreneurial capital. For instance, Kaplan and Lerner (2010) found that more than $60 \%$ of true IPOs had venture financing. Considering only $1 / 6$ of $1 \%$ of all companies are venture backed, this represents a powerful source of high potential, fast-growing, innovative companies. Further, venture backed companies also have a large impact on the overall economy. Gornall and Strebulaev (2015) found that companies previously backed by VCs account for $44 \%$ of the research and development spending among US public companies. Thus, the demographic trends of entrepreneurs who had access to venture capital represent those of a vital source of economy-wide innovation.

\section{Gender and Ethnicity Trends for Entrepreneurs and VCs}

\subsection{Summary Statistics}

Table I provides a summary of the data for both entrepreneurs and venture capitalists in our sample aggregated across the entire period from 1990 to mid-2016. Overall, we have data on 42,502 entrepreneurs (those members of the company that VentureSoure classifies as a founder), where $91.1 \%$ are men and $8.6 \%$ are women. ${ }^{4}$ We have data on 11,555 venture capitalists with a similar gender breakdown: $91.2 \%$ are men and $8.5 \%$ are women. ${ }^{5}$ This type of gender segregation has been documented anecdotally in the popular press.

\footnotetext{
${ }^{3}$ For entrepreneurs, $108(0.3 \%)$ of them are missing gender and $189(0.4 \%)$ of them are missing ethnicity. For VCs, 25 $(0.2 \%)$ of them are missing gender and $40(0.4 \%)$ of them are missing ethnicity.

${ }^{4}$ We do not make the important distinctions between "woman" and "female" in this paper. This in no way means that we equate these two concepts, but we acknowledge that addressing these distinctions is beyond the scope of this paper.

${ }^{5}$ Note that the percentages don't add up to $100 \%$ because a small fraction of entrepreneurs and venture capitalists with gender ambiguous names could not be found on web searches.
} 
Gompers Mukharlyamov, Weisburst, and Xuan (2017) documented that nearly 80\% of venture capital firms had never hired a female investor. ${ }^{67}$

Patterns of ethnic concentration are also apparent. For entrepreneurs, 79.6\% are White, where the largest ethnic minority is Asian, representing 15.8\%. Hispanic (3.8\%) and African American (0.4\%) are severely underrepresented relative to their proportions in the general population. Within the venture capital community, an even higher percentage are White (86.3\%), while Asian venture capitalists make up a smaller percentage (10.6\%) than they do for entrepreneurs. Hispanic and African American investors represent even smaller fractions of the venture capitalists at $2.5 \%$ and $0.3 \%$.

Overall, we observe a general lack of gender and ethnic diversity among the entrepreneur and venture capitalist communities, where the imbalance is somewhat worse for venture capital. Among ethnic minorities, however, Asian populations represent the largest share.

\subsection{Time Series Trends}

In this section, we explore the time series changes in the entry intensities of women and ethnic minorities in our data. For entrepreneurs, we classify the entry of an entrepreneur as the year the startup receives its first venture capital financing. Anyone listed as a "founder" in the portfolio company is considered an entrepreneur. For venture capitalists, because we can only identify a venture capitalist when they take a board seat at a portfolio company, the entry date is recorded as the first time they do so. ${ }^{8}$ We cannot observe when the individual was actually hired at the venture capital firm. Similarly, because typically only partner level venture capitalists get to sit on boards of a portfolio company, we only observe senior hires.

Compared to measuring the diversity of the entire stock of entrepreneurs and venture capitalists, we focus here on measuring their entry rates. We choose to do this not only because it is challenging to observe the stock (it is hard to observe when an entrepreneur leaves their firm or a venture capitalist retires), but also

\footnotetext{
${ }^{6}$ Moreover, we will see later that the female venture capitalists on average make fewer deals than their male counterparts, representing $7.0 \%$ of the board seats taken up by venture capital investors.

${ }^{7}$ No other survey or popular press article has ever looked at the entire population of venture capitalists and entrepreneurs. Most accounts have been relatively small, cross sectional surveys done for popular media consumption.

8 Since the average venture capitalist in our sample makes on four deals, we only record the entry of the venture capitalist based on the first deal.
} 
because the entry rate is a more sensitive measure to track the changes in demographic trends. The stock of venture capitalists and entrepreneurs will represent the sum of all the past barriers to entry and differences in supply. However, one must take necessary precautions while comparing it with other stock variables such as the labor force proportions.

\subsubsection{Gender Trends}

As described in the introduction, Figure 2 plots the gender breakdown of entering entrepreneurs and venture capitalists from 1990 to mid-2016 (averaged over every 5 years) and shows that female investors made little progress over the past 25 years. Over this period, women represent more than $45 \%$ of labor force participants consistently. Meanwhile, the proportions of entering female entrepreneurs and female venture capitalists remain extremely low.

For women entrepreneurs, the entry rate was around $7 \%$ in the 1990 s and early 2000 s, and rose gradually to about $11 \%$ since then. For women venture capitalists (VCs), the rate was around $6 \%$ in the early 1990s and rose to around 9\% in the late 1990s, but stayed at the same level ever since, displaying no secular trends. Hence, the trend for women entrepreneurs is mildly positive, while for women VCs it is non-existent. In a sharp comparison, the proportion of women in high skilled occupations such as medicine and law experienced dramatic increases during this period and are substantially higher in 2016.

\subsubsection{Ethnicity Trends}

For entrepreneurs, the percentage of minorities has steadily increased from 1990 to present, driven primarily by the growth of Asian entrepreneurs, and to a lesser extent also by Hispanic entrepreneurs, as shown in Figure 9. Hispanic entrepreneurs grew from 1\% in the early 1990 to almost 5\% by 2016, although this is still lower than their representation in the labor market entry pool: $9 \%$ in the early 1990 and 16\% post 2010. Meanwhile, Asian entrepreneurs grew from $9 \%$ to $18 \%$ in the same period, while their fraction of labor market entry increased from $3 \%$ to $5 \%$. Hence, Asians are consistently over-represented among entrepreneurs comparing to their underlying labor force proportions by a factor of around three times. Finally, 
African American entrepreneurs remain an extremely small fraction of the entrepreneurial pool, with virtually no presence in the early 1990 s and still less than $1 \%$ by 2016 , despite being a stable $12 \%$ of the labor force.

For venture capitalists, Figure 10 shows that the level of ethnic diversity is even worse than that of entrepreneurs, while they exhibit broadly similar ethnic patterns and growth trends. Hispanic venture capitalists grew from $1 \%$ to $3 \%$ over this period, while Asian venture capitalists started at $6 \%$ and grew rapidly to $15 \%$. African American venture capitalists, however, remain a tiny fraction and are less than $1 \%$ by 2016. Similar to entrepreneurs, Asians venture capitalists are over-represented compared to their labor force share, while Hispanics are under-represented and African Americans remain severely under-represented. Observing such vastly different levels of representation among the minority groups, in the remainder of the analyses, we will separate out the experience of Asians from those of the under-represented minorities, namely, Hispanics and African Americans.

\subsubsection{Gender and Ethnicity Interactions}

In this section, we explore the interaction between gender and ethnicity, i.e, is the experience of women similar across various ethnicity groups. Given the mild growth in entry rate of women entrepreneurs, we can see from Figure 11 Panel A that it is driven by the sizable increase in the entries of White female entrepreneurs from $5.3 \%$ to $7.5 \%$, as well as moderate increases of Asian female entrepreneurs from $1.6 \%$ to 2.6\%. The contributions of Hispanic and African American women remain very small percentages.

However, for women venture capitalists, Figure 11 Panel B shows that there is actually little secular change in the entry rates of White women over the past 25 years. Meanwhile, the growth in minority women venture capitalist is driven by a steady increase in Asian female venture capitalists from $0.2 \%$ to $1.5 \%$. Similar to what we saw for entrepreneurs, Hispanic and African American women remain very small percentages of venture capital industry entry.

Moreover, it is also interesting to note that female representation is generally higher for Asians than for Whites. Throughout this period, $11 \%$ of Asian entrepreneurs are women, while only $8 \%$ of White 
entrepreneurs are women. This pattern is similar for venture capital. Asian women represent roughly $50 \%$ greater percentages of Asian VCs than do White women.

Hence, the interaction of gender and ethnicity shows that White female entrepreneurs and Asian female venture capitalists are the drivers for the small level of improvement in gender diversity. Meanwhile, the base rates for women participation are moderately higher for Asians than Whites.

\subsection{Industry Patterns}

In this section, we examine the industry patterns of gender and ethnicity representation within the venture capital and entrepreneurial sectors. These patterns may help identify critical mechanisms that affect diversity. Venture-financed portfolio companies are classified into industries based upon VentureSource industry codes. We group companies into seven broad industry segments: Business and Financial Services, Consumer Goods, Consumer Services, Energy and Utilities, Healthcare, Industrial Goods and Materials, and Information Technology. This categorization is based on the industry code available in VentureSource. These classifications are highly correlated with venture capital investor specialization found in Gompers, Lerner, Kovner, and Scharfstein (2010).

For entrepreneurs, the unit of observation is an entrepreneur-company pair. We have 42,478 observations. There are two important points to keep in mind. First, a given company may have multiple entrepreneurs associated with it. Second, a given entrepreneur may start multiple companies. In both cases, they will enter the data multiple times. For venture capitalists, correspondingly, the unit of observation is the venture capitalist-portfolio company pair, where we have 42,988 observations. Similarly, a venture capitalist may sit on the board of multiple deals, while a firm may have multiple venture capital investors. In both cases, they will enter the data multiple times as well. For our analysis below, we look at gender and ethnic patterns of founders and venture capitalist entry. As such, each founding event is an observation for an entrepreneur. If a firm has two founders, both are included as observations for entrepreneurial entry. If a given entrepreneur starts multiple companies, each new company will represent an entrepreneurial entry observation. Venture capitalists only enter the sample once, the first time that they take a board seat. 


\subsubsection{Gender Patterns}

We first explore the gender patterns across industries. In Table III, we see pronounced variations of gender diversity across different industries for entrepreneurs. In the entire sample, women represent $8.6 \%$ of all entrepreneurs. Certain industries have substantially more women founders. In particular, women represent $19.7 \%$ of founders in the Consumer Goods industry and 13.6\% of founders in Consumer Services. Additionally, women represent $9.8 \%$ of Healthcare entrepreneurs. On the other hand, women entrepreneurs are only $6 \%$ of Information Technology entrepreneurs, the smallest percentage in what is the largest venture capital-backed industry. These patterns are consistent with anecdotal accounts of women pursuing more entrepreneurial opportunities in companies that focus on the consumer.

Table IV explores the same patterns for gender diversity across venture capitalists sorted by industry. For venture capital, while women represent $8.6 \%$ of all venture capitalists in our individual-level data, they represent only $7.0 \%$ of the board seats taken up by all venture capitalists when the unit of observation is changed to the VC-portfolio company pair. This is driven by the fact that women, on average, have conducted fewer deals and sit on fewer boards.

In terms of industry breakdown, there are both similarities and differences between the gender patterns of entrepreneurship and venture capital. In particular, Healthcare has the highest representation of women VCs at 10.5\%. For Consumer Goods and Consumer Services, women venture capitalists make up $8.2 \%$ and $7.2 \%$, which are slightly above average, but much less pronounced than the double-digit proportions of women entrepreneurs in these consumer-focused industries. Like the representation of women entrepreneurs in Information Technology, IT also has the lowest proportion of women VCs at 5.5\%.

Our results suggest systematic differences in industry patterns of female participation in venture capital and entrepreneurship. Consumer products and services as well as Healthcare feature higher levels of female participation. IT, however, has substantially lower female presence.

\subsubsection{Ethnicity Patterns}

Like the gender patterns, the ethnicity patterns within venture capital and entrepreneurship can help shape the hypotheses that we test later in the paper. We explore the industry patterns of minority 
entrepreneurs and venture capitalists in Table V. Overall, White entrepreneurs make up for $79.6 \%$ of the entire population, while the largest ethnic minority is Asian representing 15.8\%. Table V shows that among the Asian entrepreneurs, Information Technology has the highest proportions at $19.0 \%$ and is significantly higher than all other categories. After IT, Business and Financial Services as well as Consumer Services are both between $14.8 \%$ and $15.0 \%$ Asian entrepreneurs. Many startups in these industries have high IT content as well. Among the Hispanic entrepreneurs, all industries are roughly evenly distributed with the largest category being Consumer Goods (4.4\%) which is close to the overall Hispanic average of 3.8\%. African American entrepreneurs are a very small fraction of the overall pool and each industry. Among the African American entrepreneurs, the largest category is Consumer Services $(0.8 \%)$.

Within the venture capital community in Table VI, White venture capitalists make up an even higher proportion at $86.3 \%$ than they do for the entrepreneurial sample. Asian venture capitalists make up 10.6\%, significantly smaller than Asian entrepreneurs. Among the Asian venture capitalists, the largest categories are Information Technology (11.8\%) followed by Energy and Utilities (11.5\%). Although IT remains the top industry for Asians, the pattern across other industries is different than it is for Asian entrepreneurs. African American and Hispanics represent substantially smaller proportions of the venture capital sector. African American venture capitalists do between 0 and $0.4 \%$ of deals in all sectors with Consumer Services being highest at $0.4 \%$. Hispanic venture capitalists do roughly $2 \%$ across all sectors with Consumer Goods being the largest at $3 \%$.

The comparison of venture capital and entrepreneurs ethnic breakdowns across industries provides several insights. First, ethnic minorities have lower representation among venture capitalists than they do among entrepreneurs. Second, Asians are a large fraction of Information Technology entrepreneurs and venture capitalists while industry patterns for Hispanics and African Americans are weaker. In the next section, we explore several potential explanations for the patterns we observe. 


\section{Potential Explanations}

The prior section documented that women, African American, and Hispanics are dramatically underrepresented in the entrepreneurial and venture capital communities and that their entry into these industries has not changed dramatically over the past 25 years. On the other hand, Asian have grown dramatically in both sectors and have representations in the industries that are several times their overall averages in the labor force and levels similar to other highly compensated professions.

We explore two potential types of explanations for these patterns; supply-side and social/cultural explanations. Our analysis is meant to be suggestive. Among supply-side factors would be a training mismatch between women and underrepresented minorities and the type of training/education that leads to careers in venture capital and entrepreneurship. Second, we explore social and cultural explanations for the patterns in our data. These might include implicit and explicit biases that lower female and underrepresented minorities entry into venture capital and entrepreneurship. Alternatively, differences in the career aspirations or network information effects may influence the career choices of women and underrepresented minorities.

\subsection{Potential Supply-Side Explanations}

Since becoming a successful entrepreneur or venture capitalist requires the acquisition of relevant training in terms of education and work experience, we explore the demographic trends in education and career choices to determine whether the dramatic underrepresentation of women, African Americans, and Hispanics is due to a shortage of supply of females and minorities with the relevant backgrounds. We first look at the education and career histories of venture capitalists and entrepreneurs in our sample. Then we look at the supply of women and minorities with similar backgrounds to determine whether supply is constraining entry.

\subsubsection{Overview of Education and Employment Statistics}

In Table VII we present statistics on the education backgrounds of entrepreneurs in our sample. We collect educational background from company web pages and online resume/recruiting websites. We 
observe that entrepreneurs go to a large variety of undergraduate institutions. MIT, Stanford, and UC Berkeley are the top 3 undergraduate institutions, while many of the top 20 colleges are known for their strong science and engineering departments. Interestingly, two foreign institutions, Tel Aviv University and the Technion are also among the top undergraduate colleges, highlighting the role of Israeli entrepreneurs in the entrepreneurial community. Among the entrepreneurs who obtain a post-graduate education, only $30 \%$ of them have MBAs, but the vast majority $(70 \%)$ of entrepreneurs have non-business post-graduate degrees, further suggesting the relevance of a technical background. The top 20 institutions make up $40 \%$ of all entrepreneurs with non-business post-graduate degrees, with Stanford, MIT, Harvard, UC Berkeley and USC in the top five. The areas of concentration for entrepreneurs can be seen in Table VIII for both undergraduate and non-MBA graduate degrees. The choice of undergraduate and graduates institutions is reflected in degree choices. The vast majority of undergraduate concentrations are in science and engineering related fields. For graduate degrees, the pattern is even stronger. The vast majority of non-MBA graduate degrees are in engineering, science, and math.

In terms of entrepreneurs' work experience, Table IX shows the critical role of technology experience, nine out of the top ten past employers are technology giants such as Microsoft, IBM, Sun, Google, Oracle, Cisco, Intel, and Apple. As documented in Gompers, Lerner and Scharfstein (2005), the most prolific "spawners" are originally venture-backed companies themselves. The other two sources of entrepreneurs are universities (Stanford, MIT) as well as global consulting firms (McKinsey, Accenture). The top 20 past employers account for $13 \%$ of all entrepreneurs.

Overall, the education and employment backgrounds of our entrepreneurs indicate a strong pattern. The majority of entrepreneurs come to the table with strong science and engineering backgrounds having received advanced degrees and work experience in major technology companies. A substantial minority of the entrepreneurs in our sample, however, come with strong business backgrounds and an MBA.

We next turn to the backgrounds of venture capitalists in our sample. In Table $\mathrm{X}$ we see that more liberal arts colleges are represented for undergraduate degrees. Harvard, Stanford, and the University of Pennsylvania are the top 3 undergraduate colleges, while the top 20 colleges represent $37 \%$ of all 
undergraduate institutions, higher than that of the entrepreneurs (29\%). For those who obtain post-graduate degrees, $56 \%$ have an MBA, nearly double the proportion of entrepreneurs who have one. The concentration of the top 20 MBA programs among all MBAs is $76 \%$ : Harvard Business School alone accounts for $22 \%$ of the MBAs for venture capitalists. The top five business schools, Harvard, Stanford, University of Pennsylvania, Columbia, and Chicago, account for more than half of all MBAs.

Among the non-MBA graduate institutions that we see in Table $\mathrm{X}$, the list looks quite similar to the MBA institutions with $49.4 \%$ of degrees represented by the top five universities. Stanford, Harvard, MIT, University of Pennsylvania, and Columbia are the top five institutions. Among non-MBA graduate degrees, Table XI shows that law and medicine represent nearly half of the non-MBA graduate degrees, very different from the pattern with saw with entrepreneurs in which law and medical degrees only represented about $17.8 \%$ of non-MBA graduate degrees.

The work experience of venture capitalists also shows some difference from the experience of entrepreneurs in Table XII. Investment banks, private equity, and other venture capital firms make up for half of the top 20 past employers. This includes Goldman Sachs, Morgan Stanley, Bain, Merrill Lynch, and Lehman Brothers, suggesting that the analytical skills developed in financial firms are potentially seen as useful for the evaluation of investment opportunities. We also find a large number of consulting firms including McKinsey, Bain, BCG, Ernst and Young, and Accenture among the top employers. The remaining top 20 employers are large technology companies like Microsoft, IBM, Cisco, and Google. Overall, the number of former employers is quite high and the top 20 past employers account for $10 \%$ of all venture capitalists.

The education and work history of venture capitalists and entrepreneur provide a clear picture of two different sets of skills and training. Entrepreneurs primarily major in computer science, engineering, or the sciences, have advanced scientific degrees from strong technical universities, and have worked in major technology companies. Venture capitalists, on the other hand, have more business backgrounds. They primarily study economics, business, or finance, pursue an MBA from a top business school (or have a professional degree like a JD or MD), and have investment banking, consulting, or large technology company 
experience. This clear pattern in backgrounds allows us to explore various explanations for the low representation of women, African Americans, and Hispanics in the two sectors as well as the large and growing representation of Asians.

\subsubsection{Potential Supply-Side Explanations}

We explore the supply-side hypothesis for underrepresentation of women, Hispanics, and African Americans as well as the growth in Asians by examining the education and employment experience for these groups in the relevant degree programs and professions. Our notion of a supply-side explanation for the patterns that we see would predict that given the types of skills and training we saw in the prior section for venture capitalists and entrepreneurs, women, Hispanics, and African Americans may not pursue degrees or jobs in sectors that prepare them to be entrepreneurs or ventures capitalists. ${ }^{9}$

We obtain the number of bachelors, masters and doctoral degrees in science and engineering awarded by US institutions from the National Science Foundation as well as MBA data from the National Center for Education Statistics and the HBS admissions office. In terms of the aggregate demographic trends for different occupations, we retrieve that from the US Equal Employment Opportunity. The time series data on educational achievement is available from the early 1990s to 2012. The demographic trend for occupations is more limited. Information with detailed industry breakdown starts in 2003.

\subsubsection{Gender Trends}

\subsubsection{The Case for Women Entrepreneurs}

Our first set of supply-side tests looks at the representation of women in college and post-graduate degrees and industries that foster entrepreneurship. Since a technical education is prevalent among entrepreneurs, we look at the demographic trends for advanced degrees in these technical disciplines. In

\footnotetext{
${ }^{9}$ If we were to find a low fraction of women, Hispanics, and African Americans in the degree programs and jobs that prepare for entrepreneurship and venture capital, it would still beg the question of why those groups were not pursuing that type of experience. For now, we just compare the relative frequency of these groups who have similar backgrounds.
} 
Figure 14, we show that the proportion of science and engineering degrees granted to women has grown substantially over the past 25 years. This is true at all degree levels; bachelors, masters, and doctoral degree. For science and engineering PhDs, the fraction of degrees granted to women grew from below $30 \%$ in the 1990s to above $40 \%$ in 2012 . Women also earned $46 \%$ of the masters degrees in science and engineering, while the proportion of bachelors degrees in science and engineering is above $50 \%$. Based on the aggregate data, it does not appear there is a shortage of supply of women in entrepreneurship when it comes to relevant educational backgrounds. ${ }^{10}$

We also noted that experience at a major technology company is the most common work experience for entrepreneurs. Hence, we look at the proportion of women in software and computer related industries. In Figure 15, we see that the aggregate proportion of women in software has actually been slowly declining over the past decade, dipping below $30 \%$ by 2014 . This decline reflects not fewer women entering the software industry (the absolute number of women entering software has actually increased), but the rate of increase for women has been slower than the rate of increase for men. We see a similar decline in computer and electronics manufacturing. Therefore, even though women increasing share of science and engineering degrees, we do not observe a corresponding increase in the women's share in the related professions in the aggregate data we have. The data also reveal that women's experience in the investment banking industry has also been declining since 2003 while the proportion of consultants who are women has increased.

There are two observations that we can draw from the data. First, over the sample period, women have been a much lower share of entrepreneurs (especially in IT) than they are in computer science and engineering degrees or professionals in the software and computer manufacturing industry. Women entrepreneurs are about one-third to one-fourth of the fraction that they are in science and engineering degrees or professions in software/computer manufacturing. Clearly, the low level of females in entrepreneurship cannot be explained by a lack of trained and skilled women. Second, the most recent trend

\footnotetext{
${ }^{10}$ However, this does not rule out a potential mismatch between the subfields in which the degrees are obtained and the subfields conducive to entrepreneurial activities.
} 
in the software and computer manufacturing industries show movement away from greater participation that may not augur well for future increases in female entrepreneurs.

\subsubsection{The Case for Women Venture Capitalists}

In this section, we explore whether the supply of women with training and backgrounds matching the venture capital industry are in short supply. As we saw in the previous section, venture capitalists tend to have MBA degrees and experience in investment banking or consulting. Figure 14 shows that the overall fraction of MBA degrees granted to women has increased steadily from around 35\% in 1990 to 47\% in 2013. Meanwhile, for Harvard Business School (as a proxy for top MBA programs) the fraction of MBAs granted to women grew from $27 \%$ in 1990 to $36 \%$ in 2012. In 2016, the percentage of women among Harvard MBAs is $42 \%$.

Similarly, the fraction of women in occupations relevant to venture capital is quite high. Figure 15 shows that the percentage of those entering the investment banking industry who are women has declined slightly from $38 \%$ in 2003 to $34 \%$ in 2014 . Meanwhile, the fraction of those taking a position in consulting has risen slightly from $41 \%$ in 2003 to $44.5 \%$ in 2012 . In both cases, although there has not been explosive growth in women's participation, the overall proportions of women in investment banking and consulting have been five to seven times as high as it is in venture capital.

In short, for both entrepreneurship and venture capital, there is a remarkable growth of women who have obtained the relevant educational degrees. In terms of relevant job experience, the growth has not been as high and, in some cases, women's share has slightly declined, but it remains substantially higher than the fraction of new venture capital investors who are women. ${ }^{11}$ Overall, the evidence we presented in this section argues against a purely supply-side explanation for the low female levels in entrepreneurship and venture capital.

\footnotetext{
${ }^{11}$ Again, one must take caution here in interpreting the occupation data. Since it represents the stock of employees, we cannot differentiate entries from exits when it comes to their respective attribution to the overall changes.
} 


\subsubsection{Ethnicity Trends}

\subsubsection{The Case for Minority Entrepreneurs}

In this section we examine the education and work experience of ethnic minorities and compare it to the characteristics of entrepreneurs in our sample that we tabulated in the previous section. As discussed above, entrepreneurs tend to have advanced scientific or engineering degrees and have work experience in major technology companies. We first examine minority representation as a percentage of the advanced degrees in science and engineering that are granted each year. In terms of Ph.D. degrees, Figure 16 shows that the fraction of Ph.D.s granted to Asians has grown slightly (from 4.2\% of all science and engineering Ph.D.s granted to 6.1\%). Hispanic Ph.D.s have nearly doubled from around 2\% in 1990 to almost 4\% in 2012. African American Ph.D.s have grown the slowest, only increasing from about 2\% to just under 3\%. The experience of ethnic minorities in masters degrees is somewhat different. Figure 17 shows that there is a dramatic improvement in the fraction of science and engineering masters awarded to under-represented minorities. The fractions granted to African Americans and Hispanics were both about 2\% in 1990. By 2012, it had grown very rapidly to $7.5 \%$ for African Americans and nearly $6 \%$ for Hispanics. In contrast, the fraction of science and engineering masters granted to Asians was higher than other minorities in the 1990s at $6 \%$. However, it grew only modestly to about $7 \%$ in early 2000 s and displayed no secular growth afterwards.

The education data provides several observations. Underrepresented minorities have done particularly well improving their representation among science and engineering masters degrees, but have done less well at increasing the fraction of Ph.D.s. Asians grew primarily as a fraction of Ph.D.s granted in science and engineering. Part of the explanation for a difference in the rate of entrepreneurship in these ethnic minority groups could be difference in the Ph.D.s granted. This, however, cannot explain the entire experience. Asians have a much higher representation in our entrepreneur sample than they are in Ph.D. degrees while Hispanics and African Americans have much lower representation.

In terms of jobs in science and technology related fields, Figure 18 shows that the fraction of the software and computer manufacturing employment that are African Americans and Hispanics has remained very low, staying between $3 \%$ and $5 \%$ over the past decade with no discernable trend. In contrast, the 
fraction of Asians in computer and peripheral manufacturing grew rapidly from 15\% in 2003 to $25 \%$ to 2014 while the fraction of Asians in software has remained steady at $25 \% .{ }^{12}$

The employment data raises an important observation. Despite improvements in advanced degrees in science and engineering, African Americans and Hispanics are not entering sectors of the economy that spawn large numbers of entrepreneurs. Asians, on the other hand, increased their fraction of advanced science and engineering degrees only slightly, but were a large and increasing percentage of sectors that foster entrepreneurs. While we do not know what explains the difference in industry choices after receiving an advanced science and engineering degree, it is certainly important to understand this dynamic if we are to understand why underrepresented minorities remain a small fraction of the entrepreneurial talent pool. Finally, it is worthwhile noting that for all three minority groups, their representations in these job categories (software and computer manufacturing) are still higher than their representation within our sample of entrepreneurs.

\subsubsection{The Case for Minority Venture Capitalists}

We now turn our attention to understanding whether supply issues could affect the entry of minorities into the venture capital sector. As mentioned earlier, venture capitalists typically receive an MBA from a top 20 program and have experience in consulting or investment banking. Figure 19 shows an astounding increase in the growth of African American MBAs, doubling from 7\% in the mid-1990s to 15\% in 2013. Meanwhile, the fraction of MBAs granted to Hispanics also grew steadily from $3 \%$ to $7 \%$. The fraction of MBAs granted to Asians, unlike advanced degrees in science and technology, did not change markedly over the sample period. Moreover, the fraction of Asian MBAs grew moderately from $6 \%$ to $9 \%$ in 2007, but then started decreased to $7.9 \%$ in 2013.

In Figure 20 we examine the fraction of new hires in the consulting and investment banking industry that are an ethnic minority. Figure 20 shows that African Americans and Hispanics have not dramatically

\footnotetext{
12 In our dataset of entrepreneur and venture capitalist characteristics, we are not able to identify whether a given person is a US citizen or not. However, it is reasonable to believe that part of the growth of Asians in technology related jobs is driven by immigration. However, this is less of an issue for venture capital and finance related careers.
} 
increased their representation within these two sectors. The fraction of new hires in the consulting industry who are Hispanic consultants grew from $3.9 \%$ to $5.1 \%$ over the eleven-year period ending in 2014 . This change is broadly consistent with the increased flow of Hispanic MBAs. ${ }^{13}$ Similarly, the fraction of Hispanic investment bankers grew from $4.7 \%$ to $6.2 \%$. However, the fractions of African American professionals did not grow for consulting and even declined for investment banking despite the rapid growth of African American MBAs. African American's remained about 9\% of new hires in consulting and decreased from about $7.5 \%$ of new investment bankers to about $6 \%$ in 014 . On the other hand, despite an absence of growth of MBAs granted to Asians, the fraction of Asian consultants grew rapidly over this period from $11 \%$ to $19 \%$, and the fraction of Asian investment banker grew from $15 \%$ to almost $25 \%$.

These patterns raise several questions. First, there appears to be relatively little effect of changes in educational attainment on entry into venture capital. Asians did not increase their fraction of new MBAs, but increased their representation in the venture capital sector. Hispanics and especially African Americans dramatically increased their attainment of MBAs, but did not have a similar increase in venture capital entry. The trend in entry into consulting and investment banking follows the trend of the venture capital sector. Asians increased their entry into both investment banking and consulting while African Americans and Hispanics did not. Again, as with the minority entrepreneur representation, the trends in related professions that foster entry into venture capital seem to follow the same time series patterns. Similarly, we are struck by the very large divergence, especially for African Americans, between their representation of both degrees and related jobs and their fraction of new venture capitalists. African American venture capitalists are only a small fraction of what we would classify as the potential pool of new venture capitalists. In the next section we explore potential social and cultural explanations for this pattern.

\subsection{Potential Social and Cultural Explanations}

\subsubsection{Overview of State-Level Variations}

${ }^{13}$ In essence, we need to interpret the stock of consultants in relations to the flow of MBA degree holders. We assume a simplistic model where we hold constant the ratio of the consultant fractions to MBA degree fractions over time. The data would imply a turnover of $60 \%$ over this period, which is plausible. 
In this section, we explore the potential cultural and social factors that may be relevant to gender and ethnic diversity using state-level variations. There is a long literature in labor economics that looks at state level variation and how it affects labor market outcomes. Much of this literature looks at how variation in state laws or regulations affects particular groups of potential employees. For example, Bertrand and Mullainathan (2004) look at state level variation in labor market discrimination. Similarly, Beegle and Stock (2003) look at state level variation in disability discrimination laws and their effect on employment prospects for disabled workers. Gruber (1993) also uses state laws that affect mandatory maternity benefits on female employment. We do two types of analyses in this section. First, we look at the states that have the highest and lowest participation by women and ethnic minorities in venture capital and entrepreneurship. Second, we look at a variety of state measures (percent Republican, length of mandatory maternity benefits, college graduation rates, etc.) to look at correlation of these measures with representation in the venture capital and entrepreneurial pool of our groups.

In Table XIII, we summarize the variations of gender and ethnic diversity across the states. For each state, we look at the fraction of all venture capitalists and all entrepreneurs that enter our data who are female or an ethnic minority. Entrepreneurs are matched to states by looking at the headquarters location in the VentureSource data. We focus on the 28 states with more than 100 entrepreneurs. We assign venture capitalists to states based on the location of their first deal (identified by board representation) in which the venture capital firm has an office. ${ }^{14}$ We focus on the 26 states with more than 50 venture capitalists.

States show significant variation in representation of women in venture capital and entrepreneurship. The fraction of entrepreneurs who are female varies from $13.4 \%$ in Washington D.C. to $3.0 \%$ in Utah. The top five states include New York, Oregon, Connecticut, and Michigan. States while the five states with the lowest fraction of entrepreneurs who are women include Indiana, New Hampshire, Tennessee and Florida. Similarly, the fraction of venture capitalists who are female ranges from $11.4 \%$ in Washington to $4.1 \%$ in New Hampshire. The top states for women venture capitalists include Pennsylvania, Colorado, New Jersey

${ }^{14}$ We do not observe in which office location a given venture capitalist works. Hence, we assign the location based upon the first deal that is in a state in which the venture capital firm has an office. 
and Connecticut (which average 10.7\% female venture capitalists), while the bottom five states include Florida, Missouri, Utah and Maryland (which average 5.0\% female venture capitalists). The differences between the top states and bottom states are large and statistically significant.

In terms of ethnic diversity given the patterns we saw in the first section of this paper, we explore the state level variation for under-represented minorities and Asians separately. The percentage of entrepreneurs who are underrepresented minorities is highest in Florida at $11.0 \%$, followed by New York, Pennsylvania, Wisconsin, and Kansas. The top five states have $6.2 \%$ of the entrepreneurial pool that are Hispanic or African American. Hispanic entrepreneurs drive the percentages in Florida, New York, and Pennsylvania. States with the lowest level of entrepreneurs who are ethnic minorities include New Hampshire, Oregon, Minnesota, Virginia, and Washington which average 2.1\% underrepresented minorities in the entrepreneurial pool.

We also compute the percentage of entrepreneurs who are underrepresented minorities relative to the underrepresented minority population of the state. We match Hispanic entrepreneurs to the Hispanic population percentage and the African American entrepreneurs to the African American population percentages. The results suggest that the high level of underrepresented minority entrepreneurs in a state is primarily driven by higher representation in the state population. Adjusting for population averages actually reverses the state rankings, although the difference is not significant.

The top state for under-represented minority within the sample of venture capitals is Indiana at $6.1 \%$, followed by Florida, Illinois, New York, and Michigan. Among these states, Hispanics venture capitalists drive the results for Indiana, Florida, and New York and African Americans drive the results for Illinois and Michigan. $5.0 \%$ of the venture capitalists in these five states are underrepresented minorities. The bottom five states for underrepresented minority representation in venture capital in our sample are Tennessee, Missouri, New Hampshire, Wisconsin, and Pennsylvania that average less than 1.3\%. Once again, the relative rankings are reversed once we computer the representation of underrepresented minorities in the venture capital pool relative to the state population averages. Higher levels of underrepresented minorities within states are driven primarily by higher percentages of those groups living within the state. 
The pattern for Asian entrepreneurs and venture capitalists displays a different pattern. The fraction of the entrepreneurial pool that is Asian is the highest in California at $22 \%$, followed by New Jersey, Washington D.C., New York and Illinois. In these top five states, Asians represent $16.2 \%$ of the entrepreneurial pool. Similarly, the top state for Asian within the venture capital sample is also California in which $16 \%$ of all venture capitalists are Asian. The other states with the highest Asian fraction of venture capitalists are Michigan, Oregon, New Jersey and Utah. The top five states average $11.6 \%$ of the venture capital pool who are Asian. The states with the lowest level of Asians in the entrepreneurial sector include Minnesota, Utah, Tennessee, Missouri, and Ohio which collectively average 4.7\% Asian. For the venture capital industry, Tennessee, Missouri, Florida, Maryland, and New Hampshire have the lowest percentage of venture capitalists who are Asian. When we look at the fraction of venture capitalists who are Asian with the states population percentage, we see a different result from what we saw for Hispanics and African Americans. States with the highest levels of Asian in the population have the highest deviation in Asian representation in the entrepreneurial and venture capital sectors. Moreover, examining the off-diagonal entries of Table $\mathrm{X}$, we also see an interesting positive correlation between gender diversity and Asian participation for both entrepreneurship and venture capital. States with the highest level of female representation also have the highest level of Asian participation in both venture capital and entrepreneurship.

\subsubsection{Variations of State Level Characteristics}

Given the significant variations of gender and ethnic diversity across states, we examine the correlation of a variety of state-level variables with the diversity measures for entrepreneurs and venture capitalists at the state level. Our choice of state level variables is only meant to be suggestive and meant to motivate future research to explore actual mechanisms that may be at work. We are motivated to explore variables that capture social attitudes, economic well-being, education outcomes, and the protection of women's rights. We believe that these four broad areas provide fruitful insights into the broad sets of issues that could be operative. The specific variables that we explore include political leanings, unionization rates, 
religious affiliations, GDP per capita, improvements in education and state laws regarding maternity/family leave benefits.

There are several important caveats in interpreting the results in this section: The list of variables is by no means exhaustive, but simply reflects our priors about what mechanisms might be at play. Among the myriad state level variables, we choose to look at the fraction of the state that affiliates with the Republican party, the percentage of the labor force that is unionized, the fraction of the state's population that identifies with a Christian religion, the level of GDP per capita, the mandatory length of maternity/family leave benefits, and the growth in the state's college graduation rates. In the next section, we discuss why we believe that these variables are instructive for examining cultural and social factors that might play a role in influencing diversity in the venture capital and entrepreneurial sectors. While we discuss potential explanations for a relationship, we do not want to infer causality at this point. Our goal is to lay the foundation for future work on these topics.

All the regressions presented will be single variable correlations between the state-level variable and the diversity measure, not a multivariate regression. More importantly, our purpose here is not to identify causation, but rather to suggest patterns in the data that may hint at future research.

\subsubsection{Political Leanings}

We might expect that social attitudes towards gender and ethnic diversity may be related to political beliefs about the role of social policy in alleviating gender and ethnic disparities. In the recent decades, there has been an increased ideological polarization along the party lines documented for example in Abramowitz and Saunders (1998) and Layman and Carsey (2002), where the Republican Party has consistently taken conservative positions on welfare, racial, and cultural issues. To the extent that there are social and cultural differences correlated with party affiliation, we might expect that it would have effects on diversity within entrepreneurship and venture capital. Historically, Republicans have been more likely to believe that the free market should be left to sort out labor market outcomes and less likely to support policies like affirmative 
action. Hence, we expect that the percentage of registered Republicans in a state would be negatively correlated with gender and Ethnic diversity.

For this analysis, we use the self-identified party affiliation from Gallup in 2010 within each state as a percentage of the total voting age population. We tabulate the relationship between the state level variable and diversity in two ways. In Table XIV, we examine whether the difference in diversity (as measured by the difference in the average fraction of the entrepreneurial/venture capital population that is female, underrepresented minorities, or Asian) is significant between the top five states and the bottom five states. As before, we focus on the set of states that have sizable observations of both entrepreneurs and venture capitalists. Among them, the states with the highest percentages of Republicans are Utah, Pennsylvania, Georgia, Tennessee, and Arizona, which have an average percentage of the voting population identifying with the Republican Party of $31.6 \%$. The five states with the lowest percentages of self-identified Republicans are Massachusetts, Connecticut, Maryland, New York and California that average $20.0 \%$. In this case, we see that the fraction of entrepreneurs who are female is $6.3 \%$ in the five most Republican states, significantly lower than $9.5 \%$ in the five least Republican states. Similarly, the fraction of entrepreneurs who are Asian is $8.2 \%$ in the most Republican states compared with $13.6 \%$ in the least Republican states. The relationship between the Republican affiliation and female representation in the state's venture capital sector is statistically less significant, but is nominally in the same direction. For underrepresented minorities, the fraction of entrepreneurs is unrelated to the states Republican percentage. The fraction of venture capitalists that are Hispanic or African American is, however, negatively correlated with the Republican percentage.

We examine the relationship in a single-variate regression by regressing the percentage of the state's entrepreneurs/venture capitalists that are female, Asian, or an underrepresented minority on the state-level variable. In Table XV we find a significantly negative correlation between the fraction of both entrepreneurs and venture capitalists who are female and the percentage Republican. Similar patterns exist for Asians entrepreneurs. However, because the variation in the state level of Hispanic and African American representation is so low, we do not obtain any statistically significant results. These results are consistent with our predicted relationship between Republican Party identification and diversity. 


\subsubsection{Unionization Rates}

Next, we turn to the level of union membership within a state. Hunt (1999) hypothesized that unions may promote diversity. The level of unionization within a state might similarly reflect the view that social policy has a role in leveling the playing field. We would expect to see a positive correlation between the level of unionization and gender and ethnic diversity. However, since the level of union memberships could be correlated with a variety of other variables, any relationship observed here cannot be interpreted as causal.

In Table XIV, we see that the states with the highest unionization rates are New York, Michigan, New Jersey, Washington, and Illinois, averaging $21.2 \%$ in these states. Our data on the percentage of the labor force that is unionized comes from the website www.unionstats.com which publishes the data from Hirsh and MacPherson (2003). Our level of unionization averages the rate of union membership in 1990, 2000, and 2010. North Carolina, Georgia, Texas and Virginia have the lowest levels of union membership, averaging only $5.7 \%$. We see that the percentage of the entrepreneurs who are female is $9.4 \%$ in states with high unionization rates, significantly larger than $6.6 \%$ in states with low unionization rates. The difference the fraction of venture capitalists who are female is also significant; high union states have $9.4 \%$ of the venture capital industry who are female versus $6.8 \%$ in the low union states. Asian entrepreneurs and venture capitalists also fare better in states with high unionization rates, although the differences are less statistically significant. Our single variate regressions including all the states in Table XV show consistent patterns that are significant for both women and Asians. States with high levels of union membership have significantly more women and Asians in their venture capital and entrepreneurial ecosystems than do low union membership states.

\subsubsection{Religious Affiliations}

Religious beliefs can often influence social attitudes as well as social interactions. The role of religion may also play a role in social factors that influence diversity. In particular, in states with a higher percentage of the population that identifies as Christian, attitudes towards women in the workplace may be more conservative. If more women choose to forego careers outside the home in these states, there may be fewer 
women in the entrepreneurial and venture capital industries. However, religious affiliations are also correlated with many other variables, reminding us not to take the correlation here with any causal interpretation.

We get state level religious affiliation data from the 2010 Gallup survey. The states with the highest percentage of the population identified as practicing Christians are Tennessee, Texas, North Carolina, Georgia and Pennsylvania, averaging $83 \%$ as shown in Table XIV. On the other hand, Oregon, Washington, New Hampshire, Colorado, and California have the smallest proportions, averaging $70 \%$. While the differences are not statistically significant, the group of high Christian states have lower percentages of both the entrepreneurial and venture capital industry that are female or Asian. Interestingly, the fraction of entrepreneurs who are an underrepresented minority is higher in the high Christian states.

In Table XIV, our single variate regressions confirm these patterns. The fraction of the venture capital and entrepreneurial pool who are female or Asian is negatively related (and significant) to the percentage of the population that identifies as Christian. The results for underrepresented minorities goes in the opposite direction for both entrepreneurs and venture capitalists, although it is only significant for underrepresented entrepreneurs. This result may arise from the fact that Hispanics and African Americans may be more likely to affiliate with the Christian religion and, hence, states with high African American or Hispanic populations may have greater fractions of the population that are Christian as well as more entrepreneurs and venture capitalists from those ethnic groups.

\subsubsection{GDP Per Capita}

In addition to the political and social factors, we also examine measures of economic performance. States with high levels of GDP per capita may have greater resources that can be spent on programs to promote diversity in the innovation sector. This might include more money for scholarships, tax breaks for hiring, and state-funded training programs. As before, the causal mechanisms (if any) may have multiple channels. In fact, some scholars might look for the causality to run in the opposite direction. We do not intend to infer causality, only an empirical correlation with economic performance and diversity. 
We get data on state level GDP per capita from 1997-2010 (in constant 2009 dollars) from the Bureau of Economic Analysis. We average the level of GDP per capita for states across these years. We then rank states on the basis of GDP per capita. The five states with the highest GDP per capita in Table XIV are Connecticut, Massachusetts, New York, New Jersey and Washington, averaging $\$ 55,913$. The five states with the lowest GDP per capita are Florida, Arizona, Tennessee, Utah and Michigan, averaging $\$ 40,286$. The fractions of the entrepreneurs and venture capitalists in a given state who are female are higher in states with higher GDP per capita. In the high GDP per capita states, $9.5 \%$ of entrepreneurs are female versus $6.5 \%$ in the low GDP per capita states. For the venture capital sector, high GDP per capita states have 10.0\% of the venture capital pool who are female versus $6.4 \%$ in the low GDP per capital states. The case is similar for Asian entrepreneurs. In high GDP per capita states, $12.6 \%$ of entrepreneurs are Asians versus $7.4 \%$ for the low GDP per capita states. The fraction of Asian venture capitalists as well as underrepresented minority entrepreneurs and venture capitalists do not show a relationship between GDP per capita and diversity.

Single variate regressions in Table XV reveal similar patterns. The fraction of venture capitalists and entrepreneurs who are female shows a strong positive correlation with state-level GDP per capita. Similarly, the fraction of the entrepreneurial pool who are Asian also shows a positive and statistically significant relationship with the state-level GDP per capita.

\subsubsection{Improvements in Education}

There has been extensive research examining education as a determinant of economic growth including Barro (2013). We might expect that as educational attainment improves, the experience of women and underrepresented minorities in the innovation sector would improve. If there are more opportunities to receive the types of education and training that lead to careers in venture capital and entrepreneurship, then the playing field might become more level.

For each state, we calculate the percentage increase of the state population that has a college degree from 1980 to 2000 using information from the Census Bureau's Population Surveys and the 2010-2014 American Community Surveys. The five states with the largest increases in percentage of the population with college degrees are Massachusetts, New Jersey, Maryland, Connecticut, and New Hampshire, with an average 
increase of $11.4 \%$ in Table XIV. On the other hand, the states with the smallest increases in the percentage of the population with college degrees are Arizona, Utah, Texas, California, and Tennessee, with an average increase of $6.5 \%$. Although the differences in educational improvements are remarkable, there is no statistically significant difference in terms diversity outcomes between the five highest and the five lowest states. Similarly, the single variate regression using the increase in college degrees in Table XV also yield no statistically significant results.

\subsubsection{Parental Benefits}

A variety of research has examined the role of maternity benefits on the choice of employment for women. Dustmann and Schonberg (2012) provide evidence that an expansion in maternity benefits has a strong impact on mothers' return to work after childbirth. Similarly, Gottlieb, Townsend, and Xu (2016) look at changes in Canadian maternity benefits and the choice of women to start businesses. We therefore look at whether state-level variations in the mandated maternity/family leave benefits are correlated with diversity outcomes, especially for women. We expect that if the effects are causal, then only female participation in venture capital and entrepreneurship should be affected.

We obtain the benefit scores from the National Partnership for Women and Families that grades each state's laws concerning paid job protection, family and maternity leave, and flexible use of sick leave. The five states with the highest grades are California, Oregon, New Jersey, Connecticut, and Washington that have an average score of 87 as shown in Table XIV. There are seven states with the lowest grade (0): Maryland, Virginia, Georgia, North Carolina, Pennsylvania, Missouri, and Texas. We find that states with the highest grade have higher proportions of entrepreneurs who are female $(9.3 \%$ vs. $7.3 \%)$ and a higher fraction of venture capitalists who are female $(9.7 \%$ vs $7.3 \%)$ than the states with the lowest grades.

The single variate regressions in Table XV provide support for greater gender diversity. The statistical significances are moderate, while the signs are consistent for both the fraction of female entrepreneurs and female venture capitalists. Surprisingly, we find that there also appears to be a positive relationship between maternity/family leave benefits and the fraction of venture capitalists who are Asian. We do not have a clear explanation for this particular correlation. 
In summary, with at least moderate statistical significance, we find greater gender diversities are correlated with state measures of lower Republican Party affiliation, higher unionization rates, lower Christian identification, higher GDP per capita, and stronger state laws for maternity/family leave benefits. We also find broadly similar patterns between these state-level characteristics and the fractions of entrepreneurs and venture capitalists who are Asian. Surprisingly, there appear to be no strong patterns in the level of Hispanics and African American participation in venture capital and entrepreneurship and our state-level variables. This may be due, in part, to the extremely low level of representation for these ethnic minorities in the innovation sector more broadly.

These results suggest that there may be room for social and cultural factors in the heterogeneity of diversity across states. Policies that appear to be aimed at "leveling the playing field" towards women seem to actually improve gender diversity. Similarly, more liberal attitudes towards social policy seem to improve women representation as well. We cannot say, however, whether the mechanism works by increasing the predisposition of women to choose a career in venture capital and entrepreneurship or whether there is debiasing in the actual hiring decisions themselves. We also find, interestingly, that the representation of Asians in both the venture capital and entrepreneurial ecosystem are correlated with factors that also improve women's representation. While we do not intend these results to be interpreted in any causal manner, we do think that these correlations provide a fruitful foundation for future research.

\section{Discussion of Potential Models and Causal Inference}

The demographic patterns and trends surveyed in this paper have highlighted the overall lack of gender and ethnic diversity in both entrepreneurship and venture capital. Women have entered into entrepreneurship and venture capital at rates much lower than their entry rates into other highly compensated professional fields such as medicine or law. The representation of women in science and technology advanced degrees (as a precursor to entrepreneurship) and MBAs (as a precursor to entry into venture capital) are again much higher than the representation of women in the innovation sector. Also, the relative percentage of both sectors who are female has not increased measurably over the past twenty-five years. 
Similarly, the fractions of Hispanics and African Americans are also much lower than their general population compositions, despite the improvements in their educational attainments in advanced science and engineering degrees or MBA programs. While the experience of Hispanic entrepreneurs and venture capitalists has improved some, there has been no increase in the representation of African Americans in either.

These patterns stand in stark contrast to the experience of Asians who both started at a higher level of participation in entrepreneurship and venture capital, but then increased over the past two and a half decades at a substantially faster rate. The percentage of the venture capital and entrepreneurial sector who are Asian is substantially larger than their percentage in the overall population. This growth comes despite little change in the observed level of education attainment of Asians.

However, at least based on the aggregate data, we find that the lack of diversity is unlikely due to a shortage of supply of candidates with the relevant educational or industry backgrounds. Therefore, in this section, we discuss other possible explanations, ranging from demand side preferences to information and search frictions.

One potential demand-side explanation for the lack of diversity is related to the notion of "homophily", which is the tendency of individuals to associate with similar others. As surveyed in McPherson, Smith-Lovin, and Cook (2001), the notion that "similarity breeds connection" has robust and profound effects in network structures of every type, including "marriage, friendship, work, advice, support, information transfer, exchange, co-membership, and other types of relationship." A direct implication of this "birds of a feather" phenomenon is that venture capitalists prefer to hire, invest in, or coinvest with those that are similar to themselves in characteristics such as gender and ethnicity.

Indeed, Gompers, Mukharlyamov, and Xuan (2016) show that coinvestment patterns in venture capital are driven by social similarities, where venture capitalists who are more similar in terms of gender, ethnicity, school background, and work history are more likely to collaborate. Further, they also show that this homophily driven collaboration reduces performance. ${ }^{15}$

15 Cohen, Frazzini, and Malloy (2008) show that homophily also works at the school ties level in the investment management arena between buy side analysts and CEOs. 
Moreover, the typical venture capital firm is small in size, with a median of 3 partners in our dataset. Hiring decisions are made infrequently. Further, expansion in the VC industry has occurred mostly at the extensive margin (i.e., the creation of new, small (3-partner) VC firms), as opposed to the intensive margin (existing firm expansion). This could be due to optimal scale considerations given the output (e.g., the information collection, processing, etc. could work best on small nimble teams), or due to inefficiencies (e.g., industry-wide equilibrium fee structures provide incentives to maintain small teams). Thus, aggregate new hiring in this industry is driven by the (aggregated) decisions of small teams. From social psychology, small groups are both more likely to be homophilous, and more likely to have biases aggregate into expressed decision-making (Klocke (2007)). Thus, a slight - even subconscious - preference over certain demographic characteristics could aggregate into a sustained overall lack of diversity at an industry level.

Put differently, in a firm making a singleton new hire, a slight gender preference may result in the hiring of a man over a woman. Even though the gender preference can be thought of as a continuous variable and any slight bias could be small, the hiring outcome is binary. In this setting, even a very small bias towards hiring someone of the same gender or ethnicity could lead to persistent low representation from those groups not already in the venture capital industry. The aggregation of such binary outcomes across firms can result in the overall lack of diversity across an entire industry. ${ }^{16}$

Nonetheless, the demand-side explanation at the hiring level of a venture capital firm does not explain the lack of diversity among entrepreneurs, since the decision to become an entrepreneur typically does not depend on the hiring decision of any particular firm. Teams of entrepreneurs come together to exploit new ideas and innovation. There is no preexisting firm with a given gender or ethnicity makeup. One potential hypothesis is that the homophily-based hiring preferences affected the gender and ethnicity makeup of the previous jobs where entrepreneurs worked. This explanation is partially consistent with the data where we found the educational attainments of women and African Americans did not increase their participation in the occupations that are most relevant for entrepreneurship. However, it is worth noting that these technology firms tend to include large organizations, where the small-group dynamics outlined before would

16 A careful identification of the causal impact of this in the VC space is explored in Cohen, Gompers, and Wang (2016). 
not apply as acutely. Furthermore, it does not offer an explanation as to why the fractions of women and minorities in these occupations are still much higher than that the entrepreneurial and venture capital communities.

Going further, as suggested by sociologists as well as economists, in addition to homophily-based preferences on the demand side, homophily in a network could also have a large effect on the spread of information and behavior. Starting with Granovettor (1973), researchers have documented the importance of the social network in obtaining information about various occupations. The model proposed by CalvoArmengol and Jackson (2004) emphasized the implication of homophily for such access to job information leading to persistent correlations of employment across agents. Education scholars have also researched career aspirations in middle school, high school, and college and their correlation with gender and ethnicity. This work (Riegle-Crumb, Moore, and Ramos-Wasda (2010)) finds that even at an early age, there are differences in career aspirations in math and science between men and women and between various ethnic groups. Therefore, an information-based explanation predicts that a venture capital firm is more likely to encounter job candidates that are more similar to its existing employees because those types of individuals know more about the sector and may aspire to get jobs in venture capital or startups, irrespective of their demand preferences.

The information-based explanation can also be applicable to the decision to become an entrepreneur, given that the knowledge on how to pursue entrepreneurial activities is essential, while such information may be acquired through social interactions. Kerr and Mandorff (2016) shows that within-ethnicity social network interactions facilitate the acquisition of sector-specific knowledge, which lead to the clustering of entrepreneurial activities among immigrants. As such, further research using additional data measuring social interaction along gender and ethnicity lines could be useful in understanding the patterns and trends in occupational choices.

One question from both a research and a policy perspective are what types of forces can dislodge the homophily-induced inertia in these types of organizations. In the context of venture capital, if the inertia stems from subtle subconscious biases in preference in hiring, the greater awareness of these biases may 
change hiring practices. Our results in the prior section showing a relationship between more liberal social policies (unionization, lower Republican Party identification, and more liberal maternity/paternal leave policies) might be correlated with less bias in the hiring decisions for venture capitalists in those states. Similarly, these more liberal social policies may improve the information flow to women about potential careers in venture capital and entrepreneurship.

Similarly, other subtle treatment effects, as Gompers and Wang (2017) show, may induce more equitable hiring. Gompers and Wang show that when existing male partners at venture capital firms have more daughters, the probability of hiring a female investment professional goes up. A fruitful area for future research would be to examine other subtle treatments that may change these types of biases for ethnic minorities as well.

In the context of entrepreneurs, a question arises about whether the lack of female and underrepresented ethnic minority entrepreneurs is due to few venture capitalists who are female or an underrepresented minority or vice versa. We know that homophily exists in the venture capitalistentrepreneur pairs, shared gender and ethnicity are more likely to lead a venture capitalist and an entrepreneur to pair up. Does the inertia in the venture capital ecosystem create barriers for women, Hispanic, and African American entrepreneurs? This seems like a critical question to address. Alternatively, is the lack of female, Hispanic, and African American venture capitalists driven by a lack of female, Hispanic, and African American entrepreneurs? If this is the case, then policies that would promote greater information about careers in the entrepreneurial sector might increase female, Hispanic, and African American entrepreneurs and venture capitalists.

\section{Conclusion}

In this survey we document a systematic and persistent lack of female, Hispanic, and African American labor market participation in the innovation sector - through both entrepreneurs and the venture capitalists that fund them. In addition to documenting this empirical regularity, we explore its time-series evolution and cross-industry dynamics. We show that this same pattern is not present across similar highly- 
compensated, professional fields in such as medicine or law, nor in jobs with nearly identical human-capital profiles such as investment banking or consulting. We find that this empirical fact is not driven by a lack of supply of highly trained women, Hispanics, or African Americans. The representation of women, Hispanics, and African Americans in MBA programs as well as advanced science and engineering degrees has been substantially higher than their representation in the venture capital and entrepreneurial sectors for the past two decades.

We contrast this experience with that of Asians over the same time period. Asians started the time period with a much higher representation, compared to their percentage of the labor force, in the venture capital and entrepreneurial sector. That rate of participation increased dramatically as well over the past twenty-five years. This dramatic increase comes despite there being no dramatic increase in the fractions of MBA degree recipients or recipients of advanced science and engineering degrees who are Asian. Contrasting the experience of Asians with other ethnic minorities seems to be a fruitful area for future research.

We also explore geographic concentration of this underrepresentation of female, Hispanic, and African American labor market participation. Lastly, we examine the school- and prior work-based institutions out from which innovators and venture capitalists tend to emerge.

The primary goal of this survey is to document the empirical regularities and relationships in the innovation labor market that will serve researchers, policy makers, and practitioners. We hope that the summaries serve as the beginning of more formal and structured research approaches to explore these human capital phenomena. Given the primary importance of labor as a factor of production in the innovation space, the strong regularities we document regarding female and minority labor market participation represent an important feature of real-world markets for which we need to understand the causes - and perhaps more importantly - the consequences. Future research should thus in particular focus on systematic and careful identification techniques in order to the move the discussion forward in a careful and positive direction. 


\section{References}

Abramowitz, A., and K. Saunders, "Ideological Realignment in the U.S. Electorate", The Journal of Politics, 60, (1998), 634-652.

Barro, R., "Education and Economic Growth," Annals of Economics and Finance, 14-2(A), (2013) 277-304.

Bertrand, M., and S. Mullinathan, "Are Emily and Greg More Employable than Lakisha and Jamal? A Field Experiment on Labor Market Discrimination," American Economic Review 94, (2004), pp. 991-1013.

Calvo-Armengol, A., and M. Jackson, "The Effects of Social Networks on Employment and Inequality," American Economic Review, 94 (3), (2004)

Cohen, L., A. Frazzini, and C. Malloy, "The Small World of Investing: Board Connections and Mutual Fund Returns," Journal of Political Economy, 116 (2008), 951-979.

Dustmann, C., and U. Schonberg, "Expansions in Maternity Leave Coverage and Children's Long-Term Outcomes," American Economic Journal: Applied Economics, 4 (2012), 190-224.

French, K. R., and J. M. Poterba, "Investor Diversification and International Equity Markets," American Economic Review, 81 (1991), 222-226. 
Granovettor, M. “The Strength of Weak Ties,” American Journal of Sociology, 78, (1973), pp. 1360-1380.

Gompers, P., A. Kovner, J. Lerner, and D. Scharfstein, "Performance Persistence in Entrepreneurship," Journal of Financial Economics 96, pp. 18-32.

Gompers, P., J. Lerner, and D. Scharfstein, “Entrepreneurial Spawning: Public Corporations and the Genesis of New Ventures, 1986 to 1999," The Journal of Finance, 2 (2005), 577 - 614.

Gompers, P., V. Mukharlyamov, and Y. Xuan, “The Cost of Friendship,” Journal of Financial Economics, 119 (2016), 626-644

Gompers, P., V. Mukharlyamov, E. Weisburst, and Y. Xuan, “Gender Effects in Venture Capital,” Working Paper (2015).

Gompers, P., and S. Wang, "Daddy's Little Girls: The Effects of Children's Gender on Hiring and Performance in Venture Capital,” HBS Working Paper (2017)

Gornall, W. and I. Strebulaev, "Financing as a Supply Chain: The Capital Structure of Banks and Borrowers," Working Paper (2015).

Gottlieb, J., T. Richard, and T. Xu, “Experimenting with Entrepreneurship,” University of British Columbia working paper, (2016).

Gruber, J., “The Incidence of Mandated Maternity Benefits,” American Economic Review, 84(3), 1994, p. 622641. 
Hirsch, B., and D. Macpherson, "Union Membership and Coverage Database from the Current Population Survey: Note," Industrial and Labor Relations Review, 56, (2003), 349-54.

Hunt, G., "Laboring for Rights: Unions and Sexual Diversity Across Nations," Philadelphia: Temple University Press, (1999).

Kaplan, S. N. and J. Lerner, “It ain't broke: The past, present, and future of venture capital," Journal of Applied Corporate Finance 22(2) (2010), 36-47.

Kerr, W. R., and W. F. Lincoln, "The Supply Side of Innovation: H-1B Visa Reforms and U.S. Ethnic Invention," Journal of Labor Economics, 28 (2010), 473-508.

Kerr, W. R., and M. Mandor, “Social Networks, Ethnicity, and Entrepreneurship,” Harvard Business School Working Paper, (2015).

Klocke, U., "How to Improve Decision Making in Small Groups: Effects of Dissent and Training Interventions," Small Group Research, June 2007 38: 437-468

Layman G., and T. Carsey, "Party Polarization and Party Structuring of Policy Attitudes: A Comparison of Three NES Panel Studies," Political Behavior, 24 (2002), 199-236.

McPherson, M., L. Smith-Lovin, and J. M. Cook, "Birds of a Feather: Homophily in Social Networks," Annual Review of Sociology, 27 (2001), 415-444.

Riegle-Crumb, C., C. Moore, and A. Ramos-Wada, "Who Wants a Career in Science or Math? Exploring Adolescents' Future Aspirations by Gender and Race/Ethnicity," Science Education 95 (2010), 458-476. 
Figure 1. Female Ratio in Venture Capital, Entrepreneurship, Law and Medicine (1990-2015)

Figure 1 compares female participation entry rates in venture capital and entrepreneurship from 1990 to 2015 to female entry rates in law, medicine and labor force.

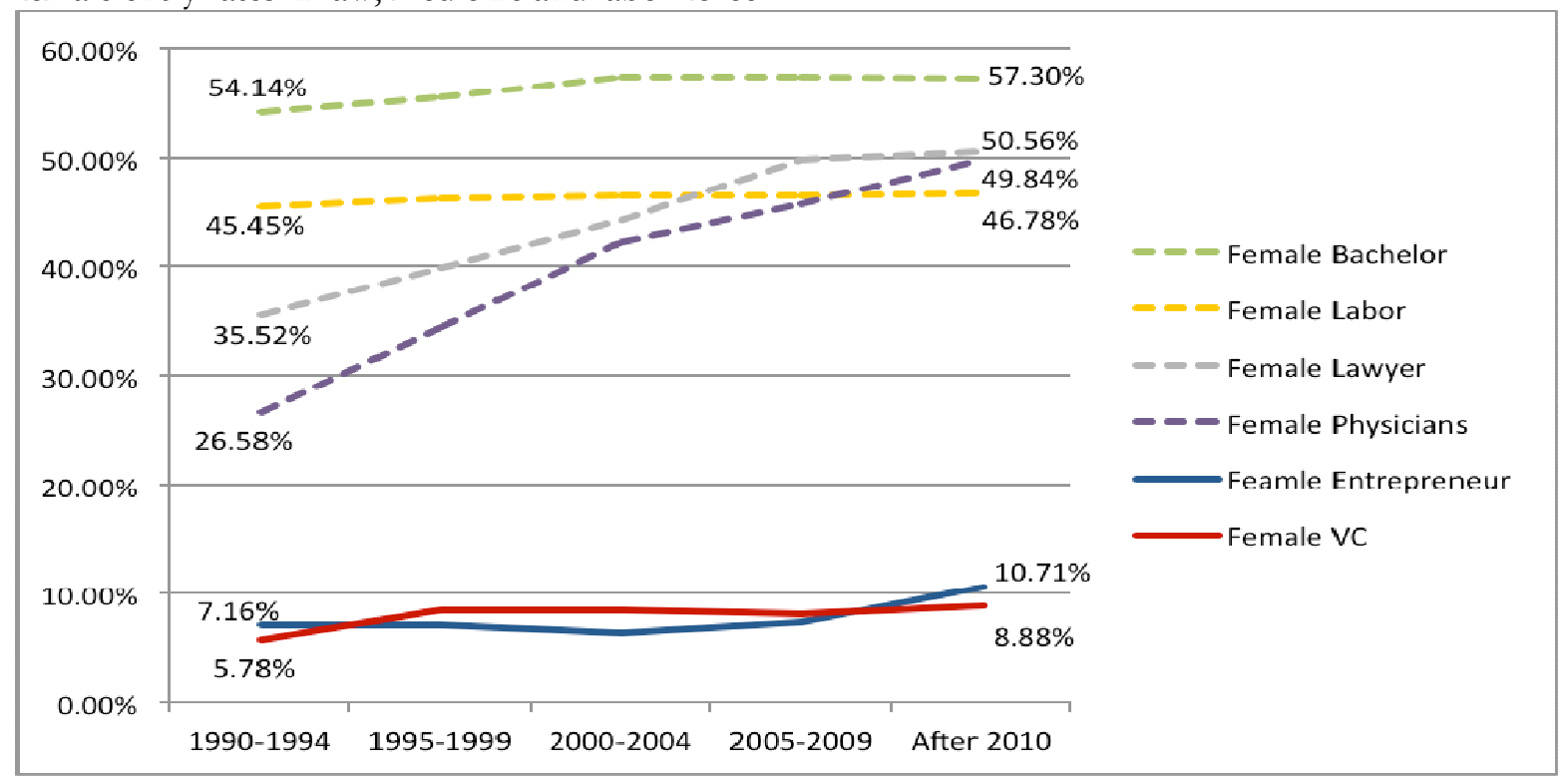

Female Bachelor Data is retrieved from http://www.bls.gov/cps/demographics.htm\#race, bachelor degree conferred to female by year. Female Labor Force data is retrieved from http://www.bls.gov/cps/demographics.htm\#women. Female lawyer/physician data is retrieved from http://www.census.gov/programs-surveys/acs/data/pums.html, female lawyers/physicians under 35 in 2000, 2005, 2010. Female lawyer/physician in 1990 is estimated from female lawyer/physician between age 35 and 50 in 2000.

Figure 2. Female Ratio in Financial Service Industry after 2010

Figure 2 compares female participation entry rates in venture capital and entrepreneurship from 2010 to 2015 to female entry rates in investment banking and consulting.

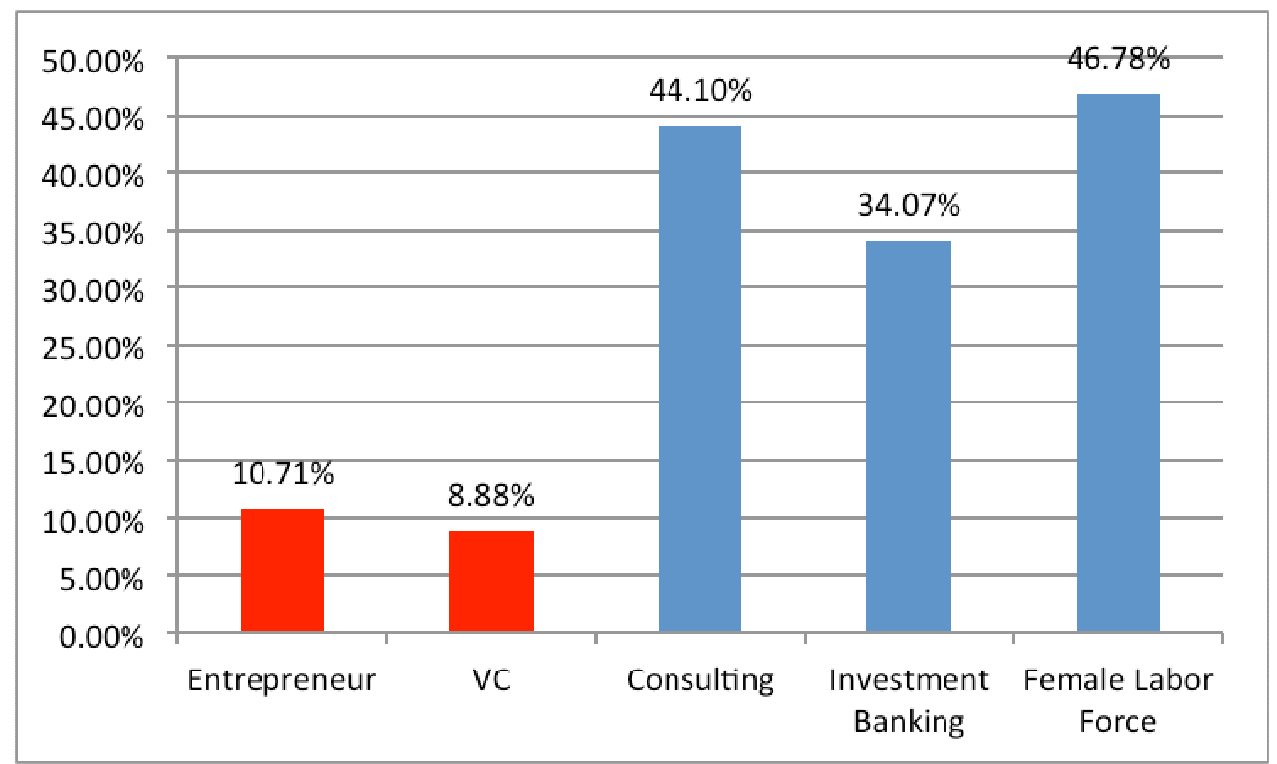

Data is retrieved from https://www.eeoc.gov/eeoc/statistics/employment/jobpat-eeo1/index.cfm 
Figure 3. African American in Venture Capital, Entrepreneurship, Law and Medicine (1990-2015)

Figure 3 compares African American entry rates in venture capital and entrepreneurship from 1990 to 2015 to African American entry rates in law, medicine and labor force.

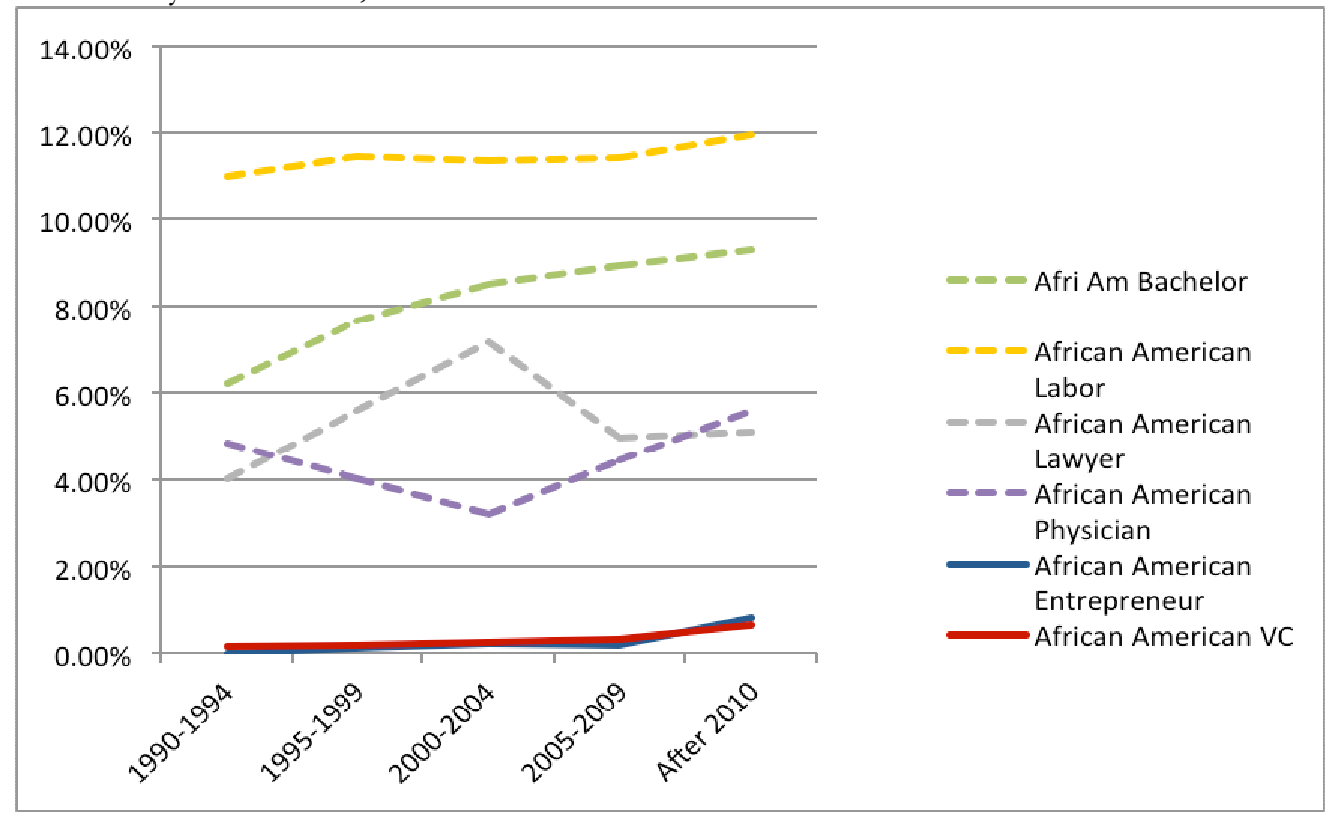

Bachelor Data is retrieved from http://www.bls.gov/cps/demographics.htm\#race, bachelor degree conferred by ethnicity. Labor

Force data is retrieved from http://www.bls.gov/cps/demographics.htm\#women. Lawyer/physician data is retrieved from http://www.census.gov/programs-surveys/acs/data/pums.html, lawyers/physicians under 35 in 2000, 2005, 2010. Lawyer/physician in 1990 is estimated from lawyer/physician between age 35 and 50 in 2000.

Figure 4. African American in Financial Service Industry after 2010

Figure 4 compares African American entry rates in venture capital and entrepreneurship from 2010 to 2015 to female entry rates in investment banking and consulting.

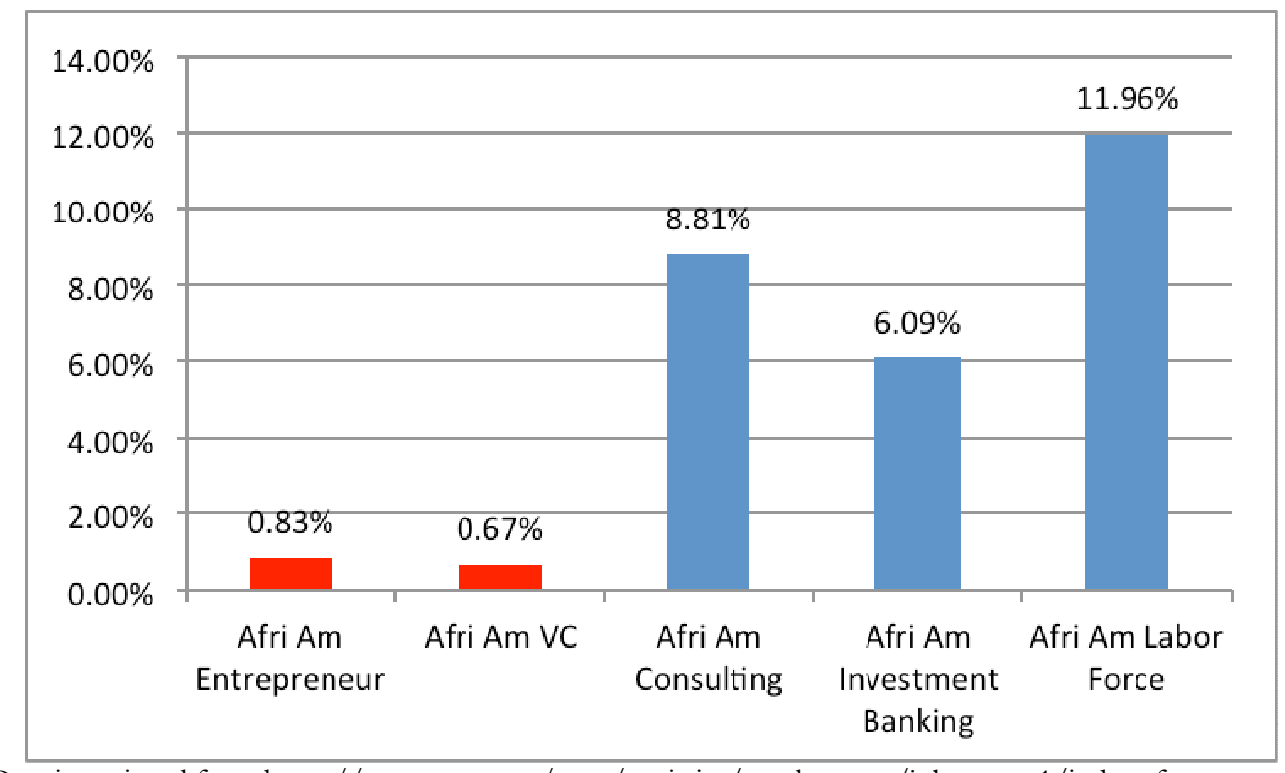

Data is retrieved from https://www.eeoc.gov/eeoc/statistics/employment/jobpat-eeo1/index.cfm 
Figure 5. Asian in Venture Capital, Entrepreneurship, Law and Medicine (1990-2015)

Figure 5 compares Asian entry rates in venture capital and entrepreneurship from 1990 to 2015 to Asian entry rates in law, medicine and labor force.

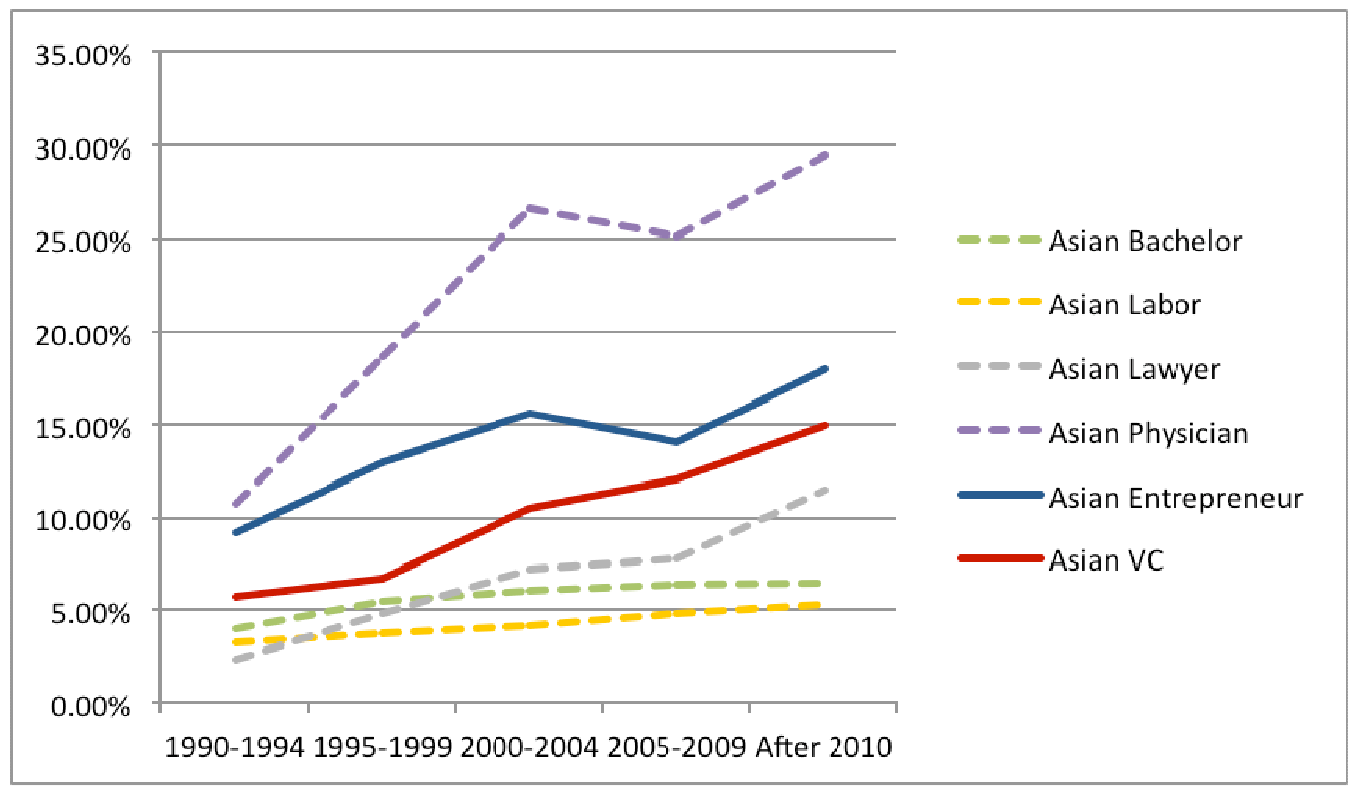

Bachelor Data is retrieved from http://www.bls.gov/cps/demographics.htm\#race, bachelor degree conferred by ethnicity. Labor

Force data is retrieved from http://www.bls.gov/cps/demographics.htm\#women. Lawyer/physician data is retrieved from http://www.census.gov/programs-surveys/acs/data/pums.html, lawyers/physicians under 35 in 2000, 2005, 2010. Lawyer/physician in 1990 is estimated from lawyer/physician between age 35 and 50 in 2000.

Figure 6. Asian in Financial Service Industry after 2010

Figure 6 compares Asian entry rates in venture capital and entrepreneurship from 2010 to 2015 to female entry rates in investment banking and consulting.

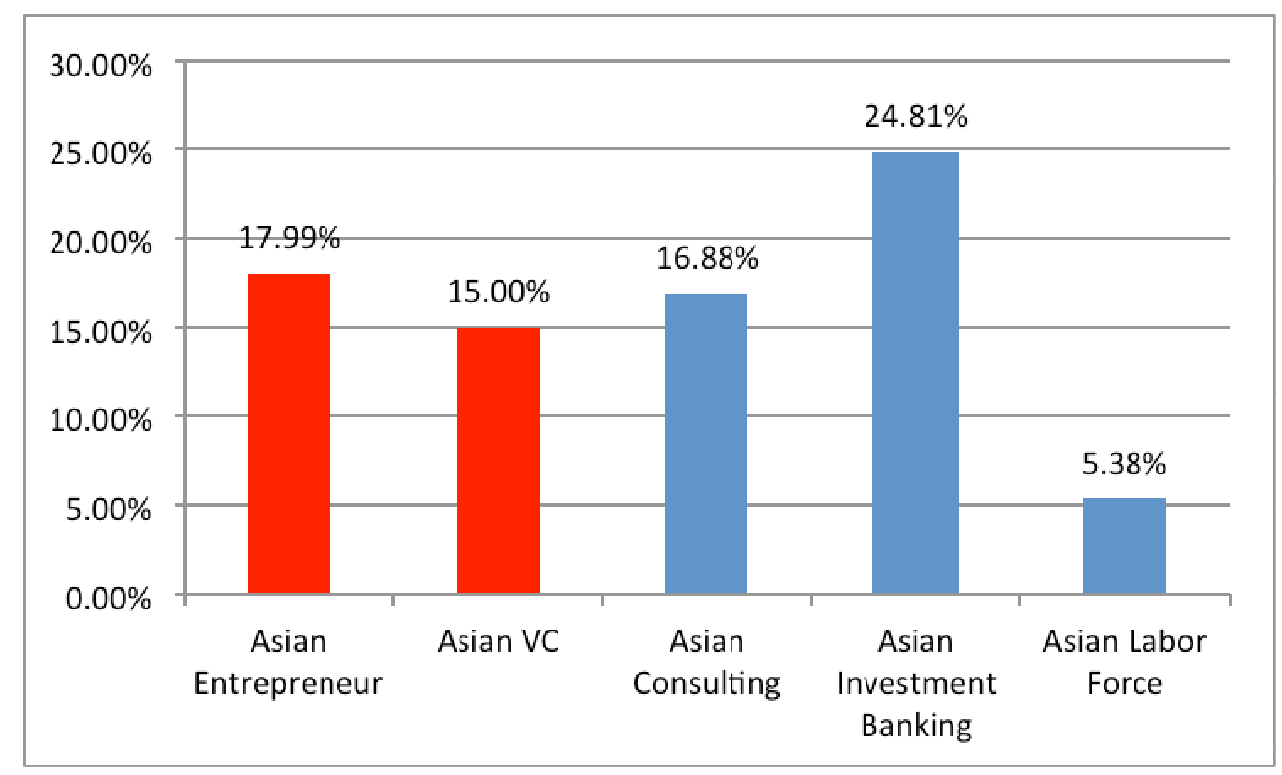

Data is retrieved from https://www.eeoc.gov/eeoc/statistics/employment/jobpat-eeo1/index.cfm 
Figure 7. Hispanic in Venture Capital, Entrepreneurship, Law and Medicine (1990-2015)

Figure 7 compares Hispanic entry rates in venture capital and entrepreneurship from 1990 to 2015 to Hispanic entry rates in law, medicine and labor force.

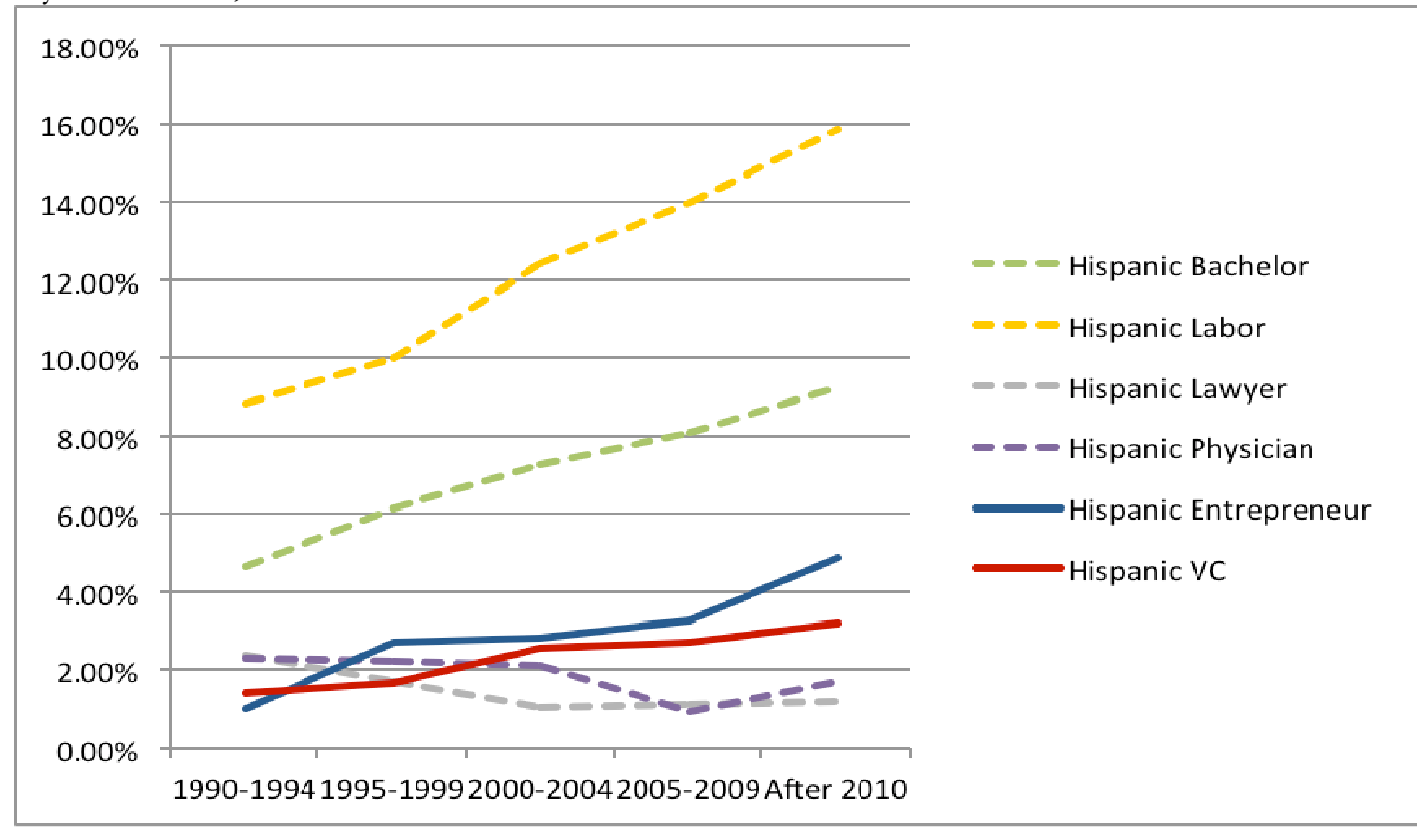

Bachelor Data is retrieved from http://www.bls.gov/cps/demographics.htm\#race, bachelor degree conferred by ethnicity. Labor

Force data is retrieved from http://www.bls.gov/cps/demographics.htm\#women. Lawyer/physician data is retrieved from http://www.census.gov/programs-surveys/acs/data/pums.html, lawyers/physicians under 35 in 2000, 2005, 2010. Lawyer/physician in 1990 is estimated from lawyer/physician between age 35 and 50 in 2000.

Figure 8. Hispanic in Financial Service Industry after 2010

Figure 8 compares Hispanic entry rates in venture capital and entrepreneurship from 2010 to 2015 to female entry rates in investment banking and consulting.

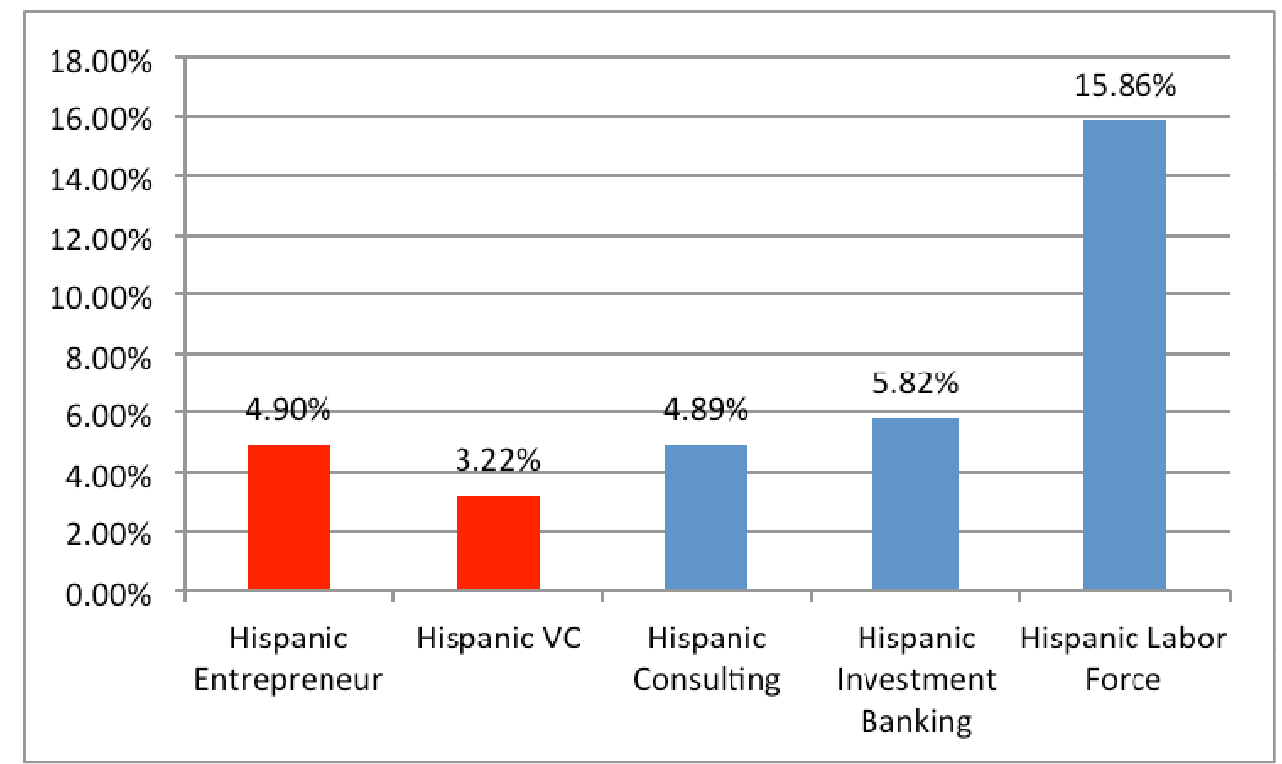

Data is retrieved from https://www.eeoc.gov/eeoc/statistics/employment/jobpat-eeo1/index.cfm 
Figure 9. Percentage of Minority Entrepreneurs Compare to Labor Force (1990-2016)

Figure 9 compares the entry rates of entrepreneurs to the labor force participation rate by ethnicity from 1990 to 2016.

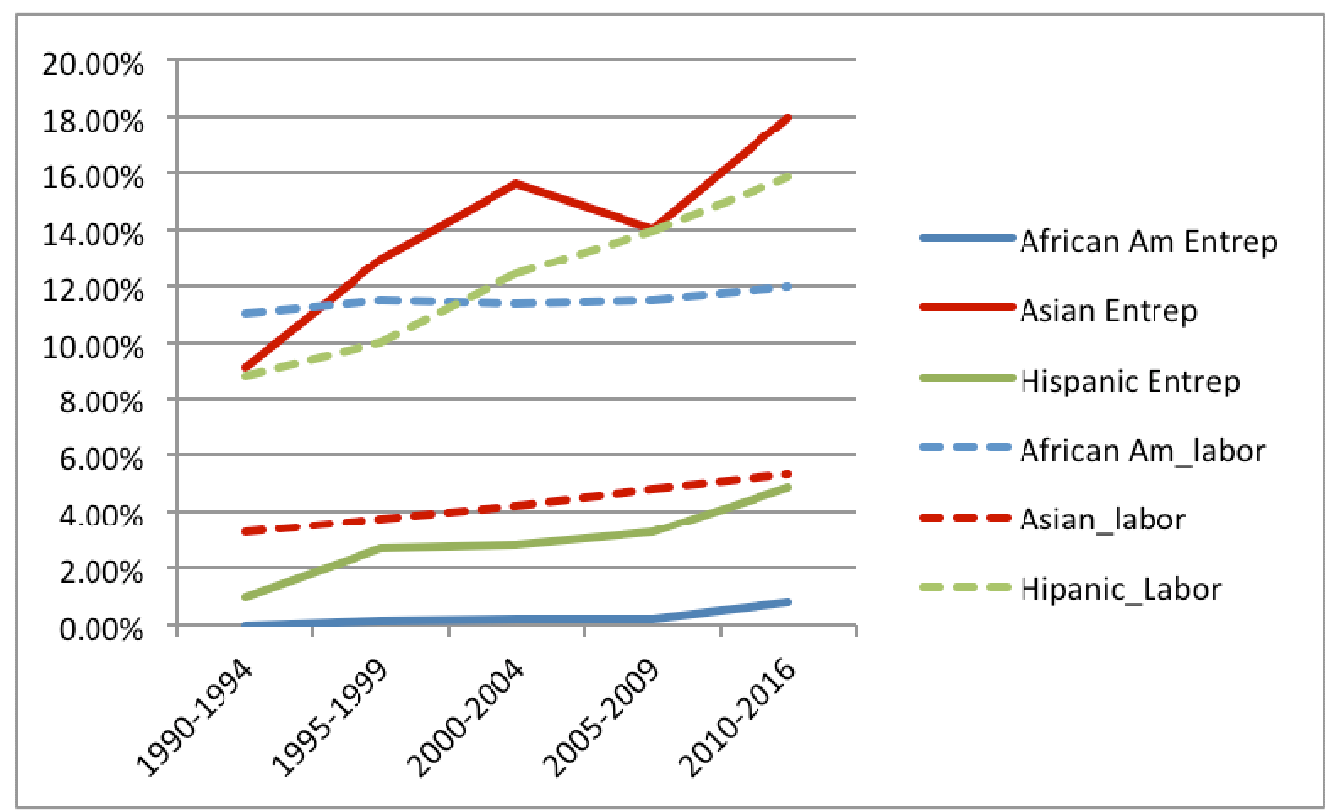

Figure 10. Percentage of Minority VC Compare to Labor Force (1990-2016)

Figure 10 compares the entry rates of venture capitalists to the labor force participation rate by ethnicity from 1990 to 2016.

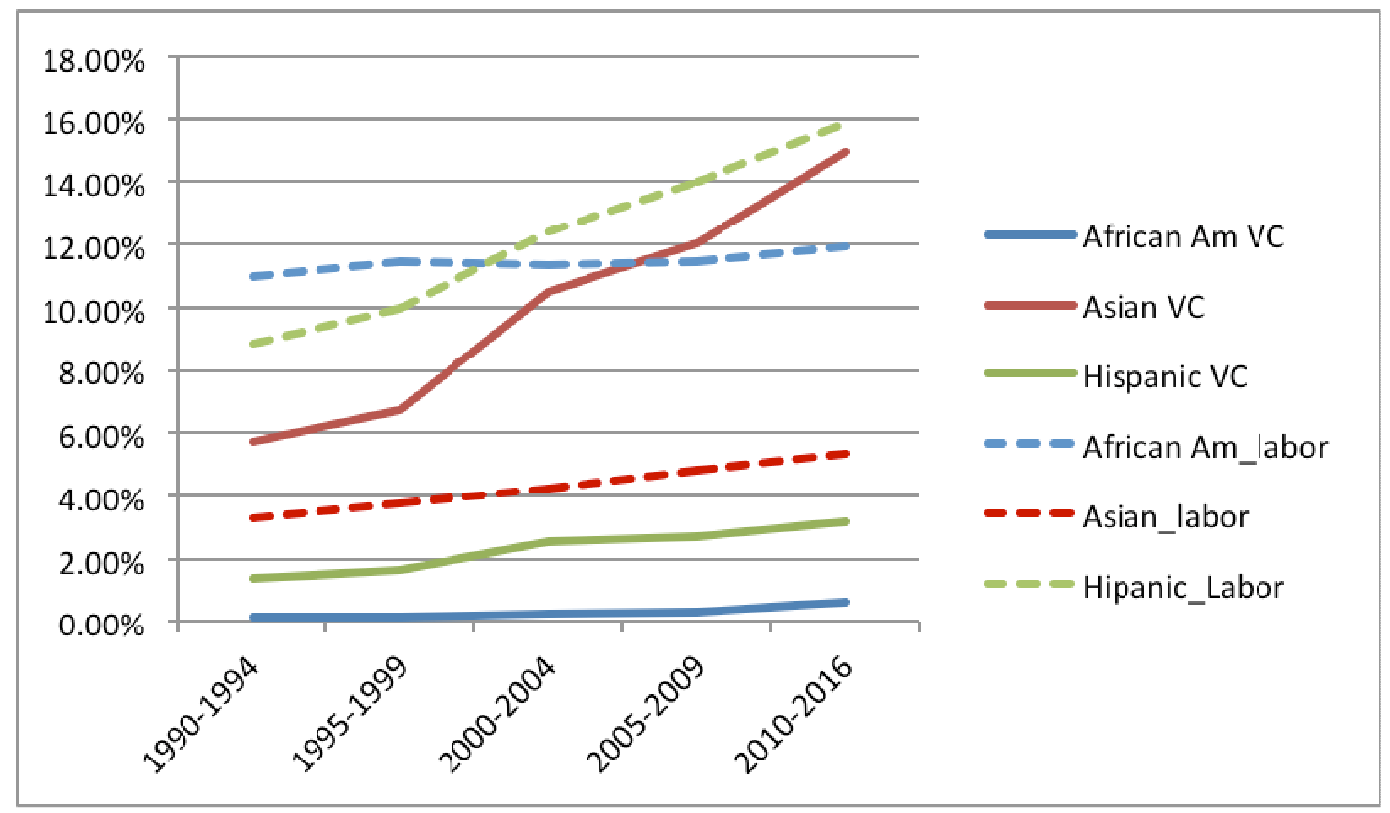

Source: http://www.bls.gov/cps/demographics.htm for minority in US labor forc 
Figure 11. Interaction of Gender and Ethnicity (1990-2016)

Figure 11 looks at the entry rates of female in venture capital and entrepreneurship by ethnicity.

Panel A: Ethnic Compositions for Female Entrepreneurs

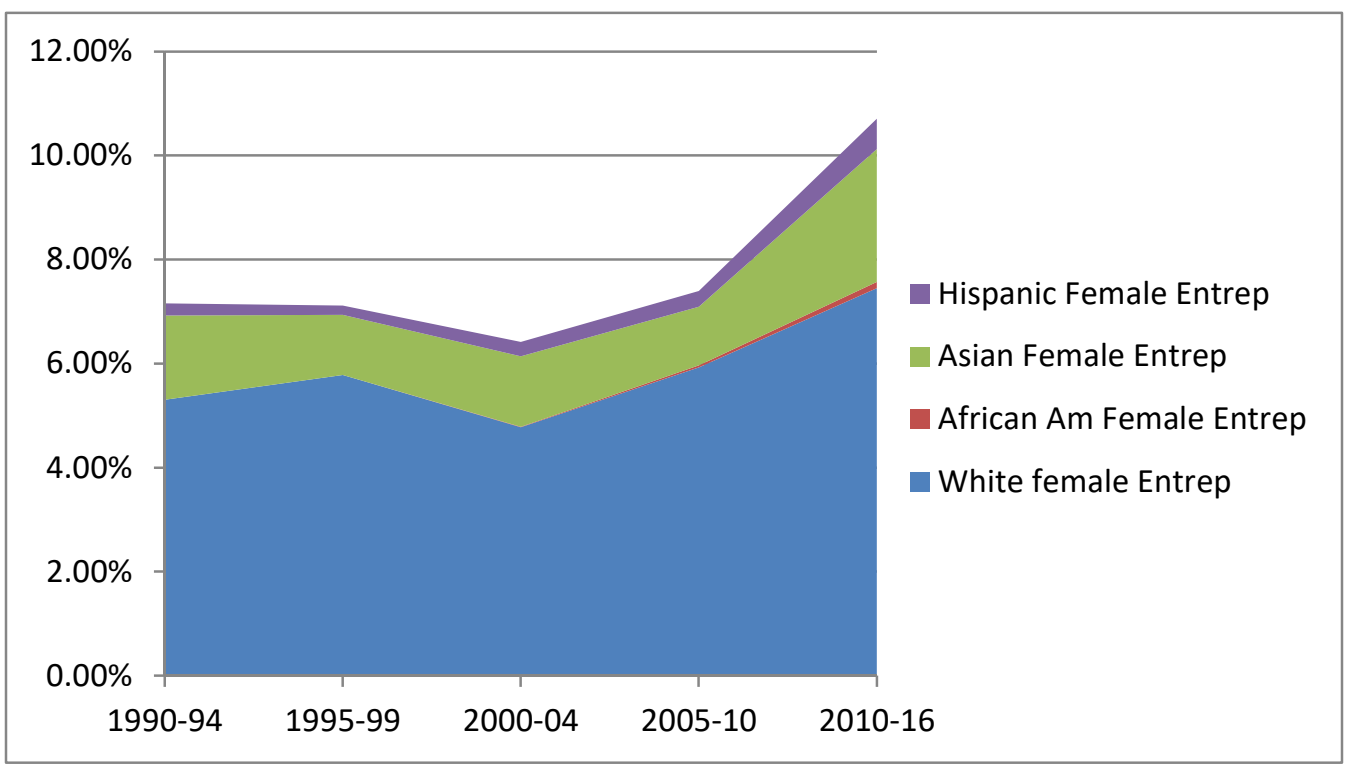

Panel B: Ethnic Compositions for Female VCs

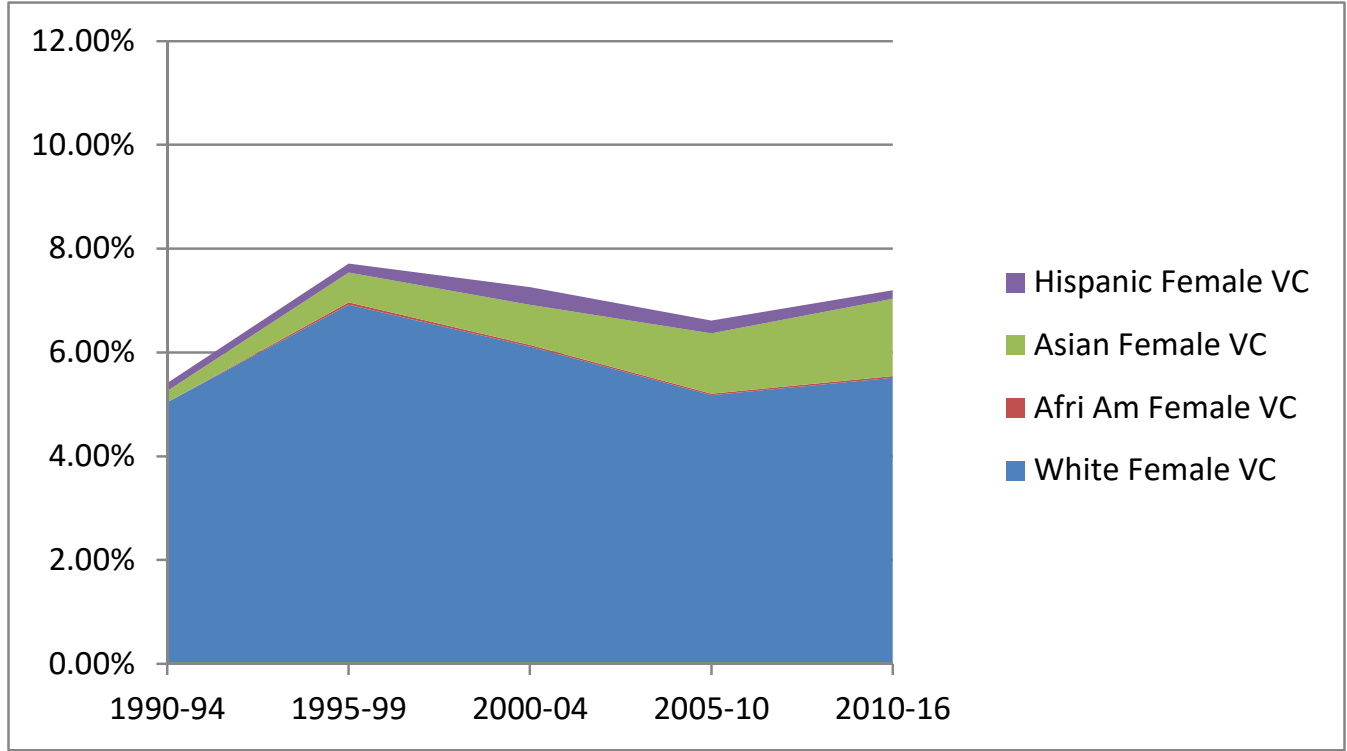




\section{Figure 12 Industry Patterns of Female Entrepreneurs and VCs}

Figure 12 looks at female participation rate in venture capital and entrepreneurship by industry.

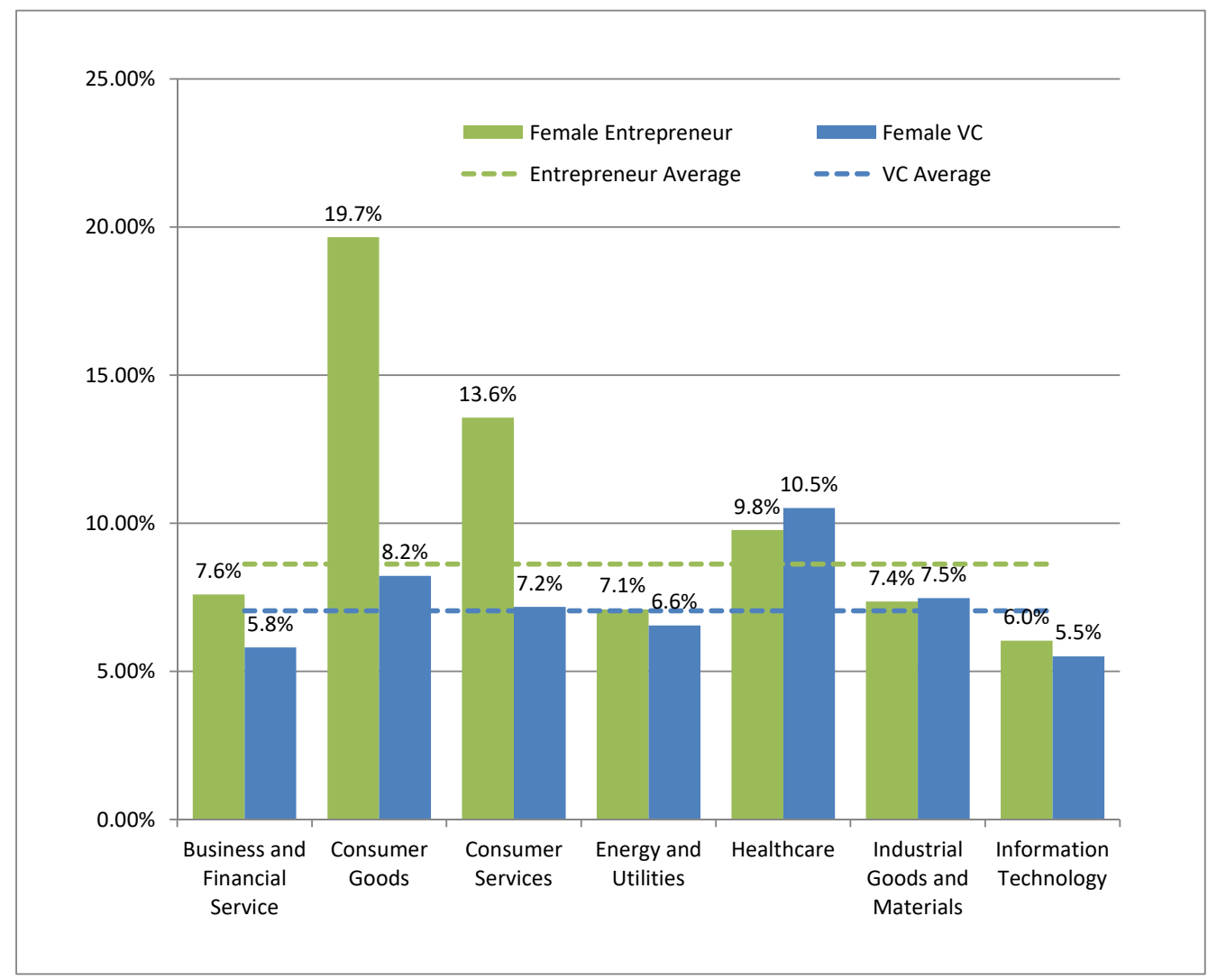


Figure 13 Industry Patterns of Minority Entrepreneurs and VCs

Figure 13 looks at minority participation rate in entrepreneurship and venture capital by industry.
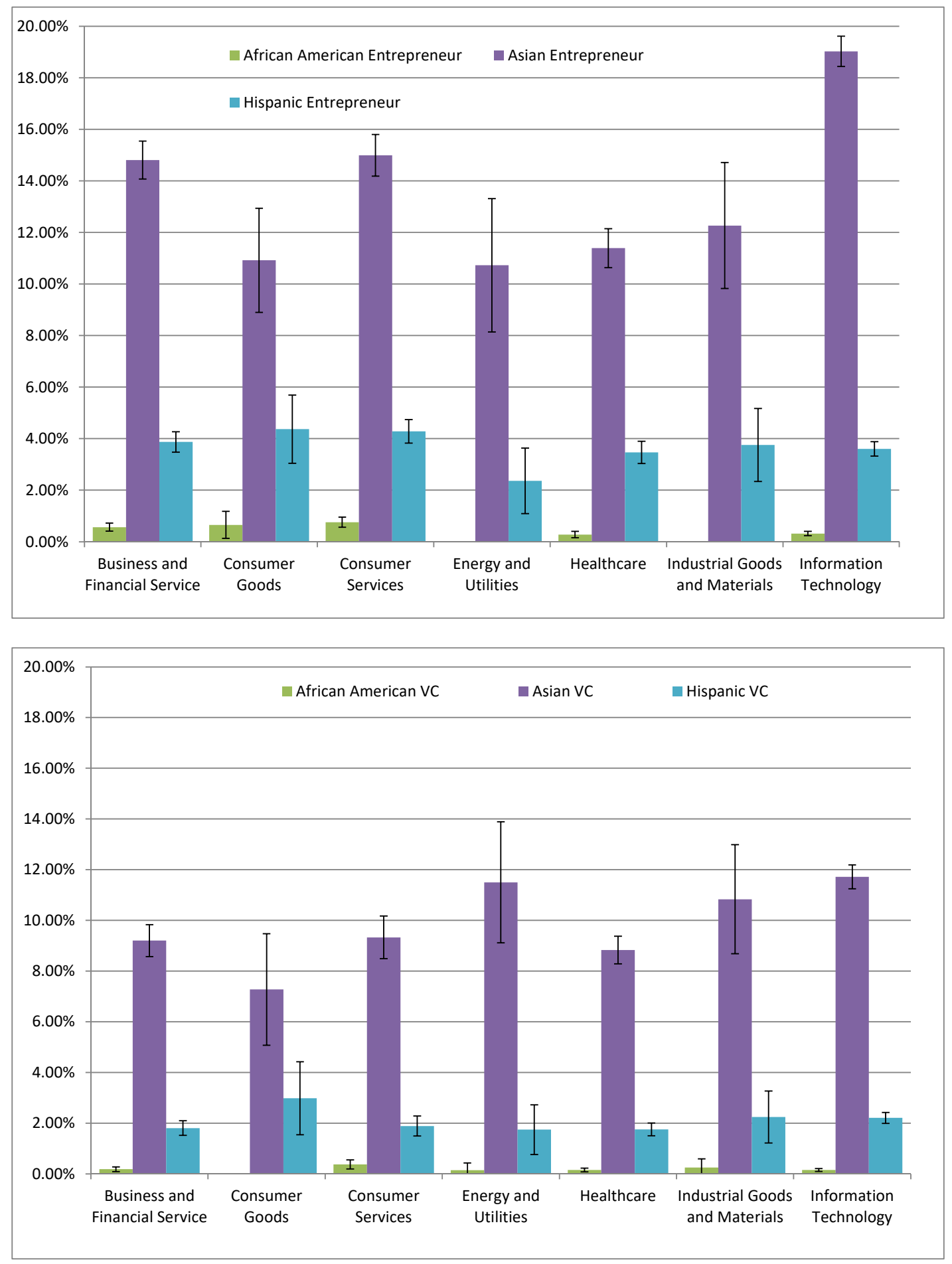

Note: The error bars denote 1.96 times the standard error. 


\section{Figure 14. Female Degree Recipients in Science and Engineering and MBA}

This figure plots the percentage of female doctorate recipients by fields. Female $P h D$ refers to the percentage of female among all US doctorate recipients. Female SE refers to the percentage of female among all US science and engineering doctorate recipients.

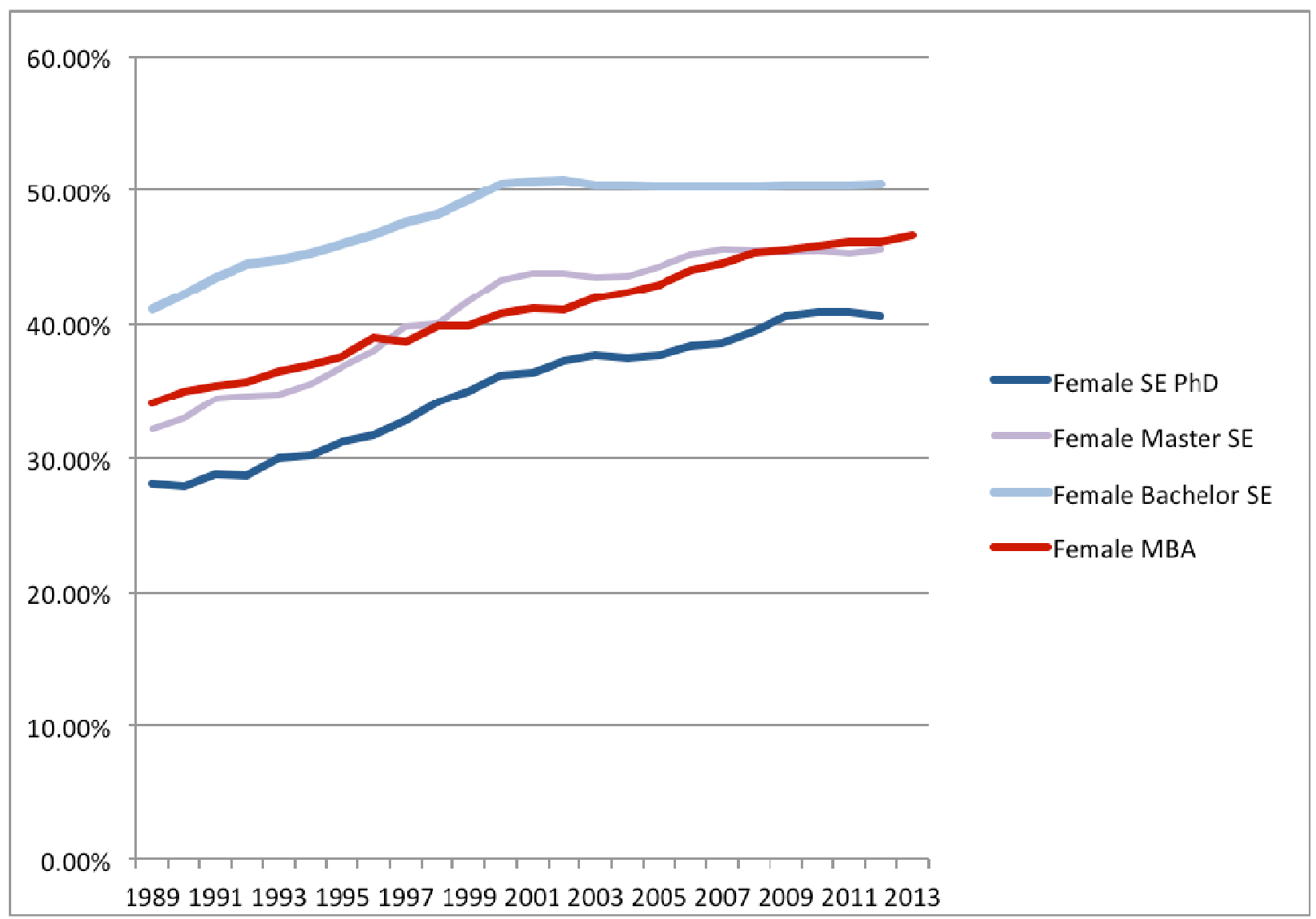

Source: Female PhD, Master, Bachelor data is retrieved from http://www.nsf.gov/statistics/degreerecipients/\#tabs-1_Female MBA data is retrieved from National Center for Education Statistics, Master's degrees conferred by degree-granting institutions, by sex, race/ethnicity, and field of study. http://nces.ed.gov/programs/digest/2015menu_tables.asp 


\section{Figure 15. Female Professionals in Technology, Consulting, Finance}

This figure plots the percentage of female professionals in IT. Female Software refers to female ratio in Software Publishing industry (NAICS 51121) and Female Computer Mfg refers to female ratio in Computer \& Peripheral Equipment Mfg (NAICS 33411). Female Consulting refers to female ration in consulting industry (NAICS 54161) and Female IB refers to female ratio in Investment Banking industry (NAICS 52311).

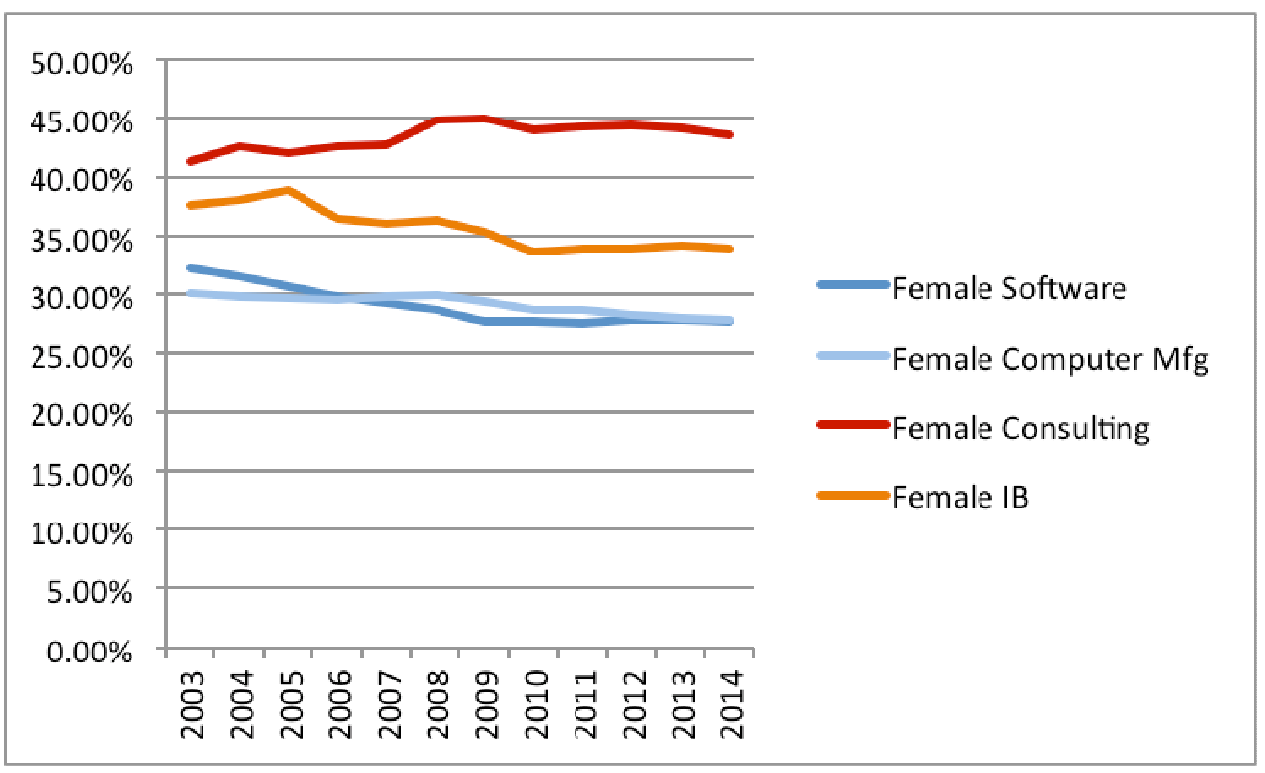

Source: https://www.eeoc.gov/eeoc/statistics/employment/jobpat-eeo1/index.cfm

Figure 16. Science and Engineering Doctorate Recipients by Minority Ethnic Groups 
This figure plots Science and Engineering doctorate recipients by US minority ethnic group. The Y axis is the percentage of SE doctorate degrees conferred to an US minority ethnic group.

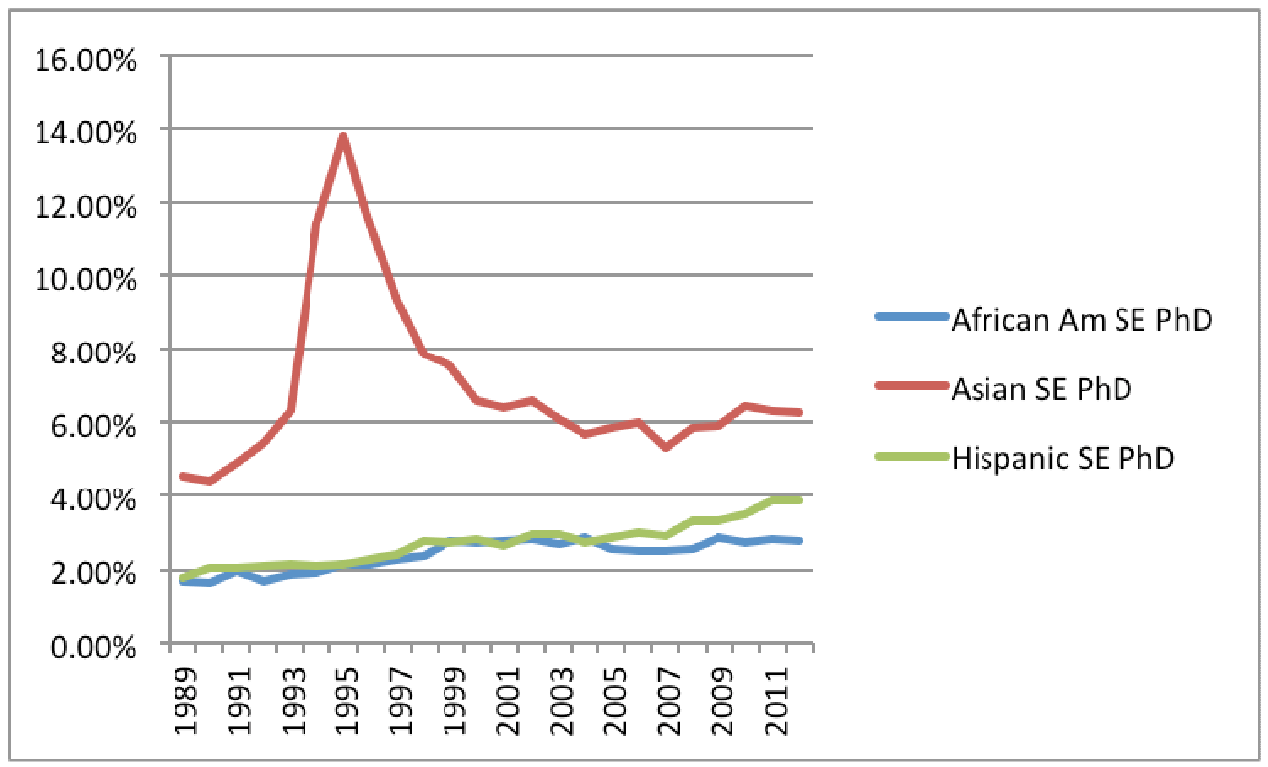

Source: http://www.nsf.gov/statistics/degreerecipients/\#tabs-1

Figure 17. Science and Engineering Master Recipients by Minority Ethnic Groups

This figure plots Science and Engineering Master Degree recipients by US minority ethnic group. The Y axis is the percentage of SE Master degrees conferred to an US minority ethnic group.

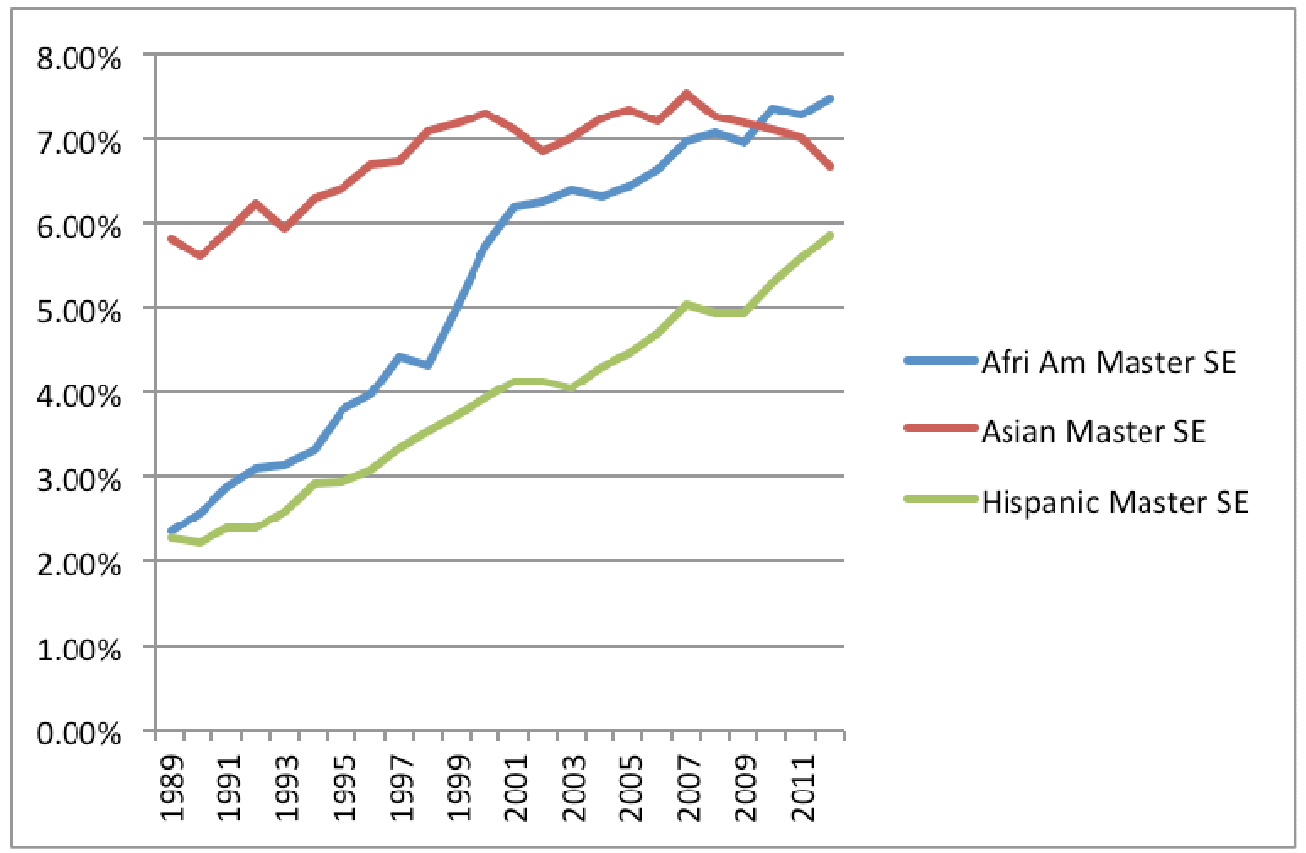

Source: http://www.nsf.gov/statistics/degreerecipients/\#tabs-1

Figure 18. Minority Professionals in Technology 
This figure plots the percentage of Asian/underrepresented minority professionals in IT. Software refers to Software Publishing industry (NAICS 51121) and Computer Mfg refers to Computer \& Peripheral Equipment Mfg (NAICS 33411). Asian refers to Asian American.

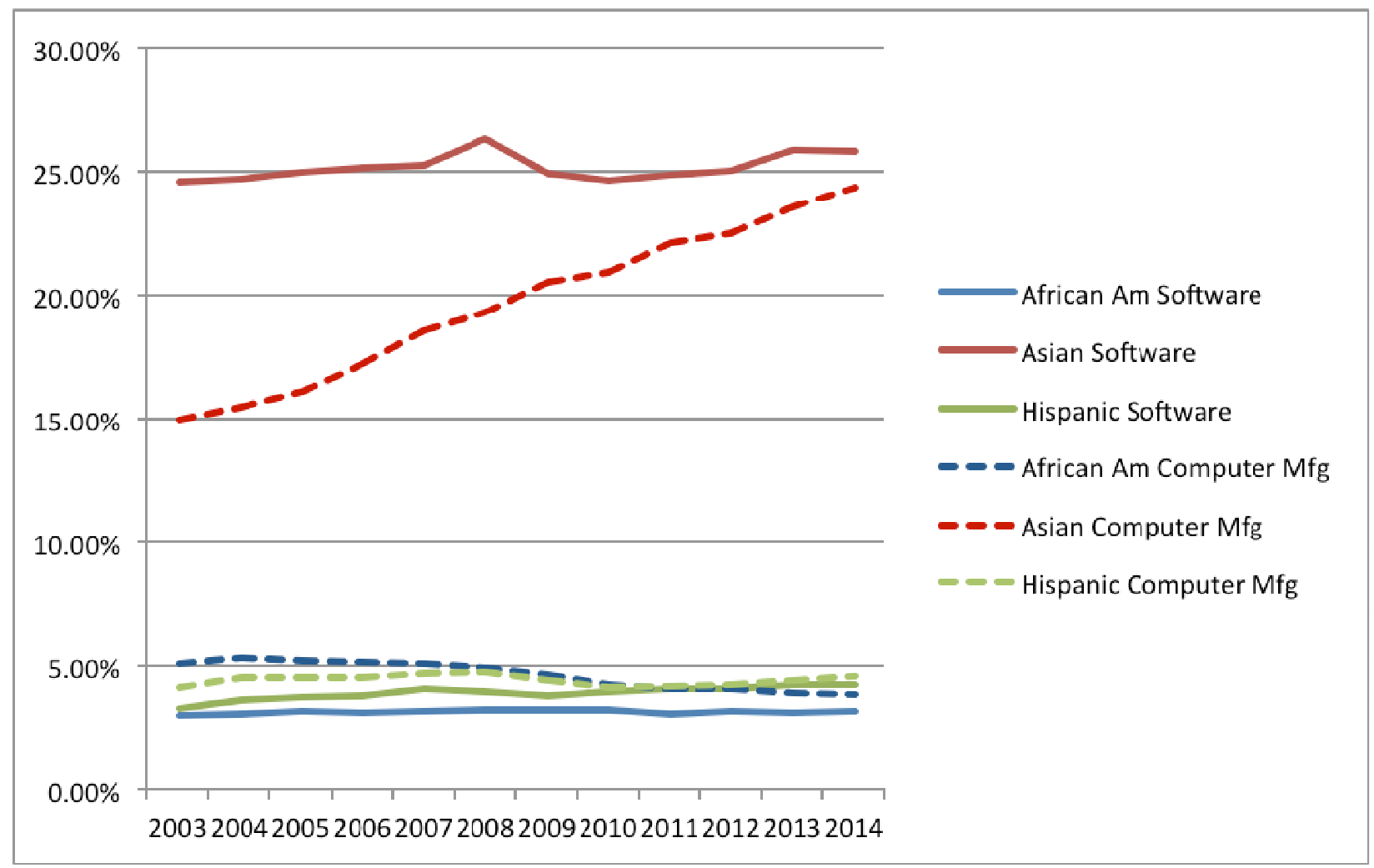

Source: https://www.eeoc.gov/eeoc/statistics/employment/jobpat-eeo1/index.cfm 


\section{Figure 19. US Masters in Business Recipients by Minority Ethnic Groups}

This figure plots MBA recipients by US minority ethnic group. The $\mathrm{Y}$ axis is the percentage of MBA degrees conferred to an US minority ethnic group.

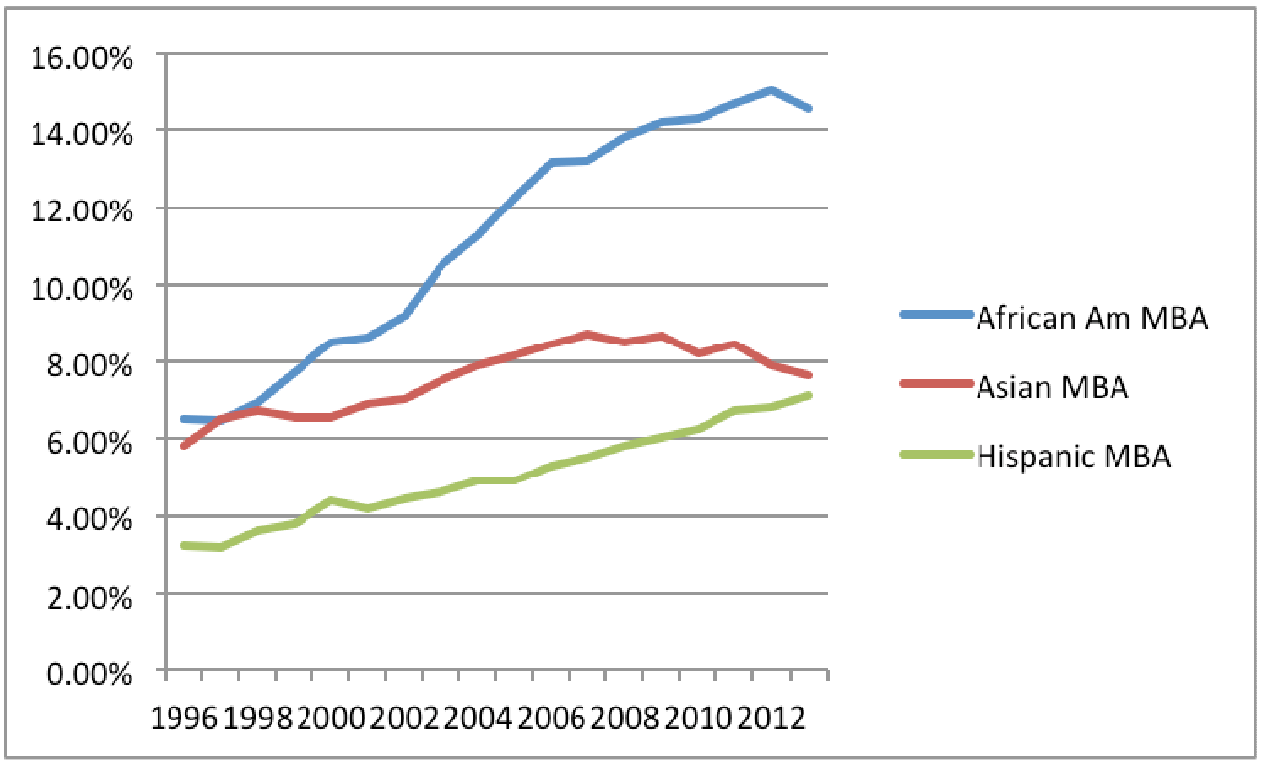

Source: National Center for Education Statistics, Master's degrees conferred by degree-granting institutions, by sex, race/ethnicity, and field of study. http://nces.ed.gov/programs/digest/2015menu_tables.asp 
Figure 20. Minority Professionals in Finance and Consulting

This figure plots the percentage of Asian/underrepresented minority professionals in Finance and Consulting. Consulting refers to consulting industry (NAICS 54161) and IB refers to Investment Banking industry (NAICS 52311). Asian refers to Asian American.

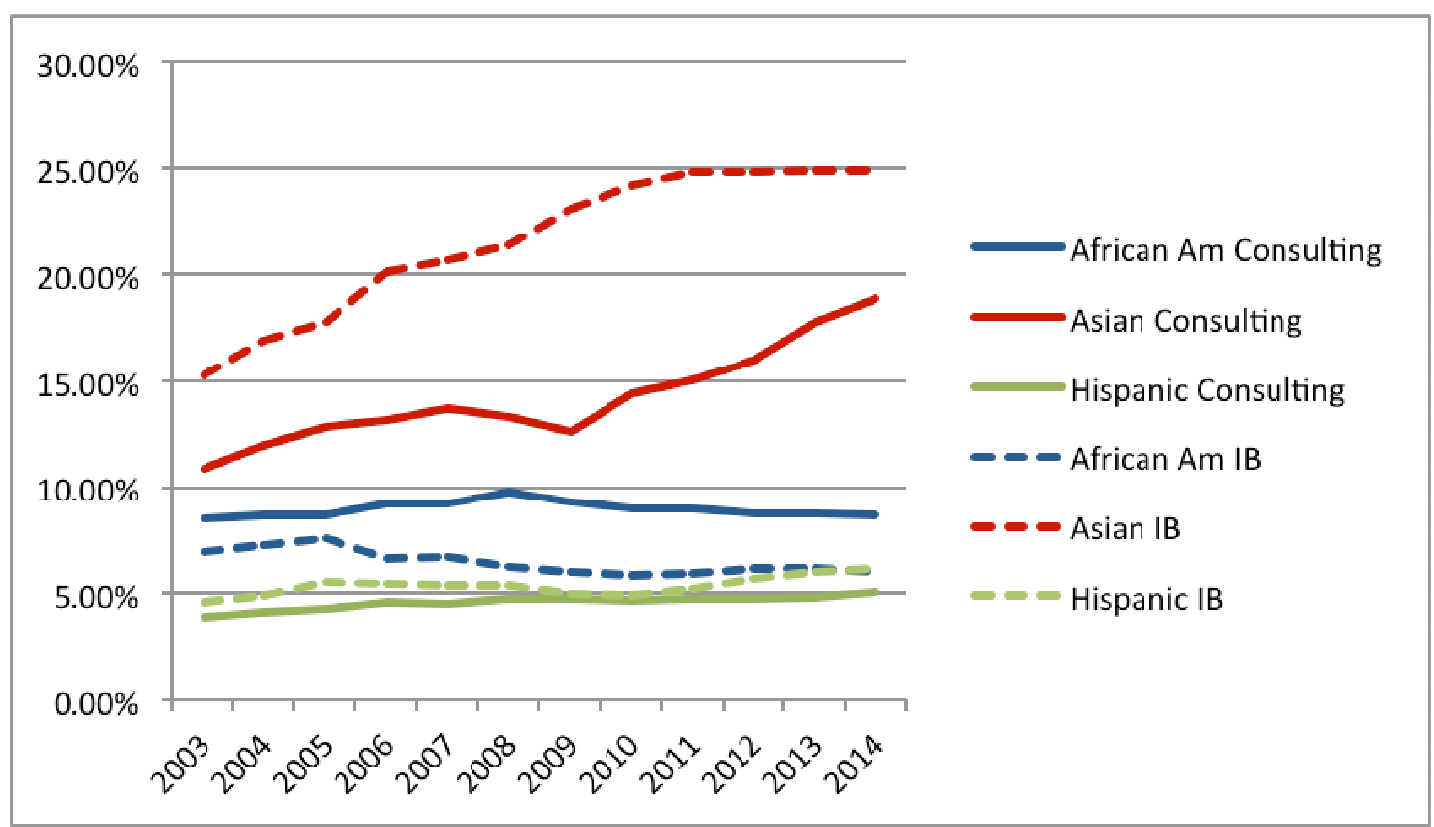

Source: https://www.eeoc.gov/eeoc/statistics/employment/jobpat-eeo1/index.cfm 


\section{Table I. Summary Statistics}

This table reports summary statistics for the sample of US entrepreneurs and venture capitalists by gender and ethnicity from 1990 to 2016. Minority is defined as the sum of African American, Asian and Hispanic. White is defined as nonHispanic White. There are a few people whose gender/ethnicity cannot be identified (less than 1\%), hence the sum of gender/ethnicity category is slightly less than the total number of observations.

\begin{tabular}{|c|c|c|c|c|c|}
\hline \multicolumn{3}{|c|}{ Entrepreneur } & \multicolumn{3}{|c|}{ VC } \\
\hline Gender & \# of obs & $\%$ of total & Gender & \# of obs & $\%$ of total \\
\hline Male & 38,727 & $91.12 \%$ & Male & 10,544 & $91.25 \%$ \\
\hline Female & 3,667 & $8.63 \%$ & Female & 986 & $8.53 \%$ \\
\hline Total & 42,502 & $100 \%$ & Total & 11,555 & $100 \%$ \\
\hline Ethnicity & \# of obs & $\%$ of total & Ethnicity & \# of obs & $\%$ of total \\
\hline $\begin{array}{l}\text { White } \\
\text { African }\end{array}$ & 33,809 & $79.55 \%$ & $\begin{array}{l}\text { White } \\
\text { African }\end{array}$ & 9,969 & $86.27 \%$ \\
\hline American & 188 & $0.44 \%$ & American & 37 & $0.32 \%$ \\
\hline Asian & 6,717 & $15.80 \%$ & Asian & 1,219 & $10.55 \%$ \\
\hline Hispanic & 1,599 & $3.76 \%$ & Hispanic & 290 & $2.51 \%$ \\
\hline Minority & 8,504 & $20.01 \%$ & Minority & 1,546 & $13.38 \%$ \\
\hline Total & 42,502 & $100 \%$ & Total & 11,555 & $100 \%$ \\
\hline
\end{tabular}


Table II Gender Diversity across Ethnic Groups (Aggregate)

Table II reports ethnicity breakdown of US entrepreneurs and venture capitalists.

\begin{tabular}{lcccc}
\hline & White & $\begin{array}{c}\text { African } \\
\text { American }\end{array}$ & Asian & Hispanic \\
\hline Entrepreneurs & & & & \\
\hline Total Obs & 33,809 & 188 & 6,717 & 1,599 \\
Female Pct & $8.1 \%$ & $12.8 \%$ & $10.8 \%$ & $10.4 \%$ \\
SE & $0.1 \%$ & $2.4 \%$ & $0.4 \%$ & $0.8 \%$ \\
& & & & \\
\hline Venture Capital & \multicolumn{5}{c}{} \\
\hline Total Obs & 9,950 & 38 & 1,218 & 289 \\
Female Pct & $8.1 \%$ & $13.4 \%$ & $11.1 \%$ & $10.0 \%$ \\
SE & $0.3 \%$ & $5.5 \%$ & $0.9 \%$ & $1.8 \%$ \\
\hline
\end{tabular}

Table III. Industry by Gender (Entrepreneurs)

This table summarizes industry by male entrepreneurs and female entrepreneurs. The observation unit is deal level. Non US deals are excluded. Some deals cannot be matched to a specific industry, hence the sum of categories is slightly less than one.

\begin{tabular}{lccc}
\hline Industry Group & Obs & Male & Female \\
\hline Business and Financial Service & 8,990 & $92.25 \%$ & $7.60 \%$ \\
Consumer Goods & 916 & $79.91 \%$ & $19.65 \%$ \\
Consumer Services & 7,518 & $86.27 \%$ & $13.57 \%$ \\
Energy and Utilities & 550 & $92.00 \%$ & $7.09 \%$ \\
Healthcare & 6,778 & $90.04 \%$ & $9.77 \%$ \\
Industrial Goods and Materials & 693 & $92.50 \%$ & $7.36 \%$ \\
Information Technology & 17,032 & $93.62 \%$ & $6.04 \%$ \\
& & & \\
Total & 42,478 & $91.12 \%$ & $8.62 \%$ \\
\hline
\end{tabular}




\section{Table IV. Industry by Gender (Venture Capitalist)}

This table summarizes industry by male VC and female VC. The observation unit is deal level. Non US deals are excluded. Some deals cannot be matched to a specific industry, hence the sum of categories is slightly less than one.

\begin{tabular}{lccc}
\hline Industry Group & Obs & Male & Female \\
\hline Business and Financial Service & 8,080 & $93.95 \%$ & $5.80 \%$ \\
Consumer Goods & 535 & $91.78 \%$ & $8.22 \%$ \\
Consumer Services & 4,555 & $92.51 \%$ & $7.18 \%$ \\
Energy and Utilities & 687 & $93.45 \%$ & $6.55 \%$ \\
Healthcare & 10,469 & $89.32 \%$ & $10.52 \%$ \\
Industrial Goods and Materials & 803 & $91.66 \%$ & $7.47 \%$ \\
Information Technology & 17,844 & $94.35 \%$ & $5.51 \%$ \\
& & & \\
Total & 42,988 & $92.84 \%$ & $7.05 \%$ \\
\hline
\end{tabular}

Table V. Industry by Ethnicity (Entrepreneurs)

This table summarizes entrepreneurs' industry by ethnicity and race. The observation unit is deal level. Non US deals are excluded. Some deals cannot be matched to a specific industry, hence the sum of categories is slightly less than one.

\begin{tabular}{lccccc}
\hline Industry Group & Obs & White & $\begin{array}{c}\text { African } \\
\text { American }\end{array}$ & Asian & Hispanic \\
\hline Business and Financial Service & 8,990 & $80.24 \%$ & $0.57 \%$ & $14.81 \%$ & $3.87 \%$ \\
Consumer Goods & 916 & $83.73 \%$ & $0.66 \%$ & $10.92 \%$ & $4.37 \%$ \\
Consumer Services & 7,518 & $79.57 \%$ & $0.76 \%$ & $14.99 \%$ & $4.28 \%$ \\
Energy and Utilities & 550 & $86.36 \%$ & $0.00 \%$ & $10.73 \%$ & $2.36 \%$ \\
Healthcare & 6,778 & $84.45 \%$ & $0.28 \%$ & $11.39 \%$ & $3.47 \%$ \\
Industrial Goods and Materials & 693 & $83.69 \%$ & $0.00 \%$ & $12.27 \%$ & $3.75 \%$ \\
Information Technology & 17,032 & $76.60 \%$ & $0.32 \%$ & $19.02 \%$ & $3.60 \%$ \\
& & & & & \\
Total & 42,478 & $79.55 \%$ & $0.44 \%$ & $15.81 \%$ & $3.76 \%$ \\
\hline
\end{tabular}




\section{Table VI. Industry by Ethnicity (Venture Capitalist)}

This table summarizes VC industry by ethnicity and race. The observation unit is VC deal level. Non US deals are excluded. Some deals cannot be matched to a specific industry, hence the sum of categories is slightly less than one.

\begin{tabular}{lccccc}
\hline Industry Group & Obs & White & $\begin{array}{c}\text { African } \\
\text { American }\end{array}$ & Asian & Hispanic \\
\hline Business and Financial Service & 8,083 & $88.61 \%$ & $0.19 \%$ & $9.20 \%$ & $1.81 \%$ \\
Consumer Goods & 536 & $89.37 \%$ & $0.00 \%$ & $7.28 \%$ & $2.99 \%$ \\
Consumer Services & 4,555 & $88.30 \%$ & $0.37 \%$ & $9.33 \%$ & $1.89 \%$ \\
Energy and Utilities & 687 & $86.46 \%$ & $0.15 \%$ & $11.50 \%$ & $1.75 \%$ \\
Healthcare & 10,473 & $89.13 \%$ & $0.15 \%$ & $8.83 \%$ & $1.76 \%$ \\
Industrial Goods and Materials & 803 & $86.67 \%$ & $0.25 \%$ & $10.83 \%$ & $2.24 \%$ \\
Information Technology & 17,844 & $85.68 \%$ & $0.15 \%$ & $11.72 \%$ & $2.21 \%$ \\
& & & & & \\
Total & 42,988 & $87.43 \%$ & $0.18 \%$ & $10.21 \%$ & $1.99 \%$ \\
\hline
\end{tabular}


Table VII. Education (Entrepreneurs)

This table summarizes education of entrepreneurs in the sample. The total number of degrees is less than the total number of entrepreneurs because some entrepreneurs are missing education history in our sample either due to they did not finish a certain degree or we cannot find it online.

\begin{tabular}{|c|c|c|c|c|c|c|c|}
\hline \multicolumn{4}{|c|}{ College } & \multicolumn{4}{|c|}{ Business School } \\
\hline & & Obs & Percent & & & Obs & Percent \\
\hline 1 & Massachusetts Institute of Technology & 426 & $3.12 \%$ & 1 & Harvard University & 586 & $16.03 \%$ \\
\hline 2 & Stanford University & 411 & $3.01 \%$ & 2 & Stanford University & 330 & $9.03 \%$ \\
\hline 3 & University of California (Berkeley) & 351 & $2.57 \%$ & 3 & University of Pennsylvania & 245 & $6.70 \%$ \\
\hline 4 & Harvard University & 341 & $2.50 \%$ & 4 & University of Chicago & 138 & $3.77 \%$ \\
\hline 5 & Cornell University & 228 & $1.67 \%$ & 5 & Northwestern University & 127 & $3.47 \%$ \\
\hline 6 & University of Pennsylvania & 218 & $1.60 \%$ & 6 & University of California (Berkeley) & 119 & $3.25 \%$ \\
\hline 7 & University of Michigan & 198 & $1.45 \%$ & 7 & Columbia University & 101 & $2.76 \%$ \\
\hline 8 & Princeton University & 174 & $1.27 \%$ & 8 & University of California (Los Angeles) & 100 & $2.74 \%$ \\
\hline 9 & Yale University & 173 & $1.27 \%$ & 9 & Massachusetts Institute of Technology & 87 & $2.38 \%$ \\
\hline 10 & University of California (Los Angeles) & 163 & $1.19 \%$ & 10 & New York University & 66 & $1.81 \%$ \\
\hline 11 & University of Illinois (Urbana Champaign) & 155 & $1.13 \%$ & 11 & Dartmouth College & 47 & $1.29 \%$ \\
\hline 12 & University of Texas (Austin) & 143 & $1.05 \%$ & 12 & Santa Clara University & 45 & $1.23 \%$ \\
\hline 13 & Tel Aviv University & 137 & $1.00 \%$ & 13 & University of Michigan & 43 & $1.18 \%$ \\
\hline 14 & Dartmouth College & 131 & $0.96 \%$ & 14 & University of Southern California & 42 & $1.15 \%$ \\
\hline 15 & Technion Israel Institute of Technology & 125 & $0.92 \%$ & 15 & Babson College & 37 & $1.01 \%$ \\
\hline 16 & Brown University & 120 & $0.88 \%$ & 16 & Duke University & 36 & $0.98 \%$ \\
\hline 17 & Duke University & 119 & $0.87 \%$ & 17 & University of Texas (Austin) & 36 & $0.98 \%$ \\
\hline 18 & Columbia University & 114 & $0.83 \%$ & 18 & University of Washington & 35 & $0.96 \%$ \\
\hline 19 & Boston University & 113 & $0.83 \%$ & 19 & Boston University & 34 & $0.93 \%$ \\
\hline 20 & University of Washington & 111 & $0.81 \%$ & 20 & Pepperdine University & 33 & $0.90 \%$ \\
\hline & Top 20 Total & 3,951 & $28.93 \%$ & & Top 20 Total & 2,287 & $62.55 \%$ \\
\hline & Sample Total & 13,657 & $100 \%$ & & Sample Total & 3,656 & $100 \%$ \\
\hline
\end{tabular}


Table VII. Education (Entrepreneurs) Continued

\begin{tabular}{rlrr}
\hline \multicolumn{3}{c}{ Graduate School (Non-MBA) } \\
\hline & Obs & Percent \\
1 & Stanford University & 732 & $8.66 \%$ \\
3 & Massachusetts Institute of Technology & 401 & $4.75 \%$ \\
4 & Harvard University & 353 & $4.18 \%$ \\
5 & University of California (Berkeley) & 236 & $2.79 \%$ \\
6 & University of Penthern California & 142 & $1.68 \%$ \\
7 & Cornell University & 140 & $1.66 \%$ \\
8 & Columbia University & 131 & $1.55 \%$ \\
9 & Carnegie Mellon University & 127 & $1.50 \%$ \\
10 & University of Illinois (Urbana Champaign) & 119 & $1.41 \%$ \\
11 & University of Michigan & 117 & $1.38 \%$ \\
12 & New York University & 111 & $1.31 \%$ \\
13 & University of California (Los Angeles) & 99 & $1.17 \%$ \\
14 & California Institute of Technology & 96 & $1.14 \%$ \\
15 & University of Wisconsin (Madison) & 87 & $1.03 \%$ \\
16 & University of Texas (Austin) & 87 & $1.03 \%$ \\
17 & University of Washington & 83 & $0.98 \%$ \\
18 & Yale University & 83 & $0.98 \%$ \\
19 & Boston University & 82 & $0.97 \%$ \\
20 & Oxford University & 76 & $0.90 \%$ \\
& Top 20 Total & 71 & $0.84 \%$ \\
& Sample Total & 3,373 & $39.91 \%$ \\
& & 8,451 & $100 \%$ \\
& & & \\
\hline
\end{tabular}




\section{Table VIII. College and Graduate Majors (Entrepreneurs)}

This table summarizes degree and majors of entrepreneurs in the sample. The total number of degrees is less than the total number of entrepreneurs because some entrepreneurs are missing education history in our sample either due to they did not finish a certain degree or we cannot find it online.

\begin{tabular}{|c|c|c|c|}
\hline & Undergraduate Majors of Entrepreneurs & Count & Percent \\
\hline 1 & Electrical Engineering & 1,205 & $14.31 \%$ \\
\hline 2 & Computer Science & 1,020 & $12.12 \%$ \\
\hline 3 & Economics & 585 & $6.95 \%$ \\
\hline 4 & Business & 580 & $6.89 \%$ \\
\hline 5 & Engineering & 387 & $4.60 \%$ \\
\hline 6 & Mathematics & 356 & $4.23 \%$ \\
\hline 7 & Physics & 342 & $4.06 \%$ \\
\hline 8 & Mechanical Engineering & 302 & $3.59 \%$ \\
\hline 9 & Biology & 278 & $3.30 \%$ \\
\hline 10 & Chemistry & 241 & $2.86 \%$ \\
\hline 11 & Finance & 213 & $2.53 \%$ \\
\hline 12 & Computer Engineering & 203 & $2.41 \%$ \\
\hline 13 & Political Science & 189 & $2.24 \%$ \\
\hline 14 & Accounting & 175 & $2.08 \%$ \\
\hline 15 & History & 147 & $1.75 \%$ \\
\hline 16 & Marketing & 144 & $1.71 \%$ \\
\hline 17 & Psychology & 122 & $1.45 \%$ \\
\hline 18 & English & 116 & $1.38 \%$ \\
\hline 19 & Chemical Engineering & 108 & $1.28 \%$ \\
\hline \multirow[t]{3}{*}{20} & Communication & 94 & $1.12 \%$ \\
\hline & Total & 8,419 & $100.00 \%$ \\
\hline & Graduate Degrees of Entrepreneurs & Count & Percent \\
\hline 1 & Master (Non MBA) & 4,058 & $59.89 \%$ \\
\hline 2 & $\mathrm{PhD}$ & 2,012 & $29.69 \%$ \\
\hline 3 & JD & 433 & $6.39 \%$ \\
\hline 4 & $\mathrm{MD}$ & 268 & $3.96 \%$ \\
\hline & Total (Non MBA) & 6,776 & $100.00 \%$ \\
\hline
\end{tabular}

Note: 3,656 out of 14,134 Entrepreneurs have an MBA degree. 
Table VIII. College and Graduate Majors (Entrepreneurs) Continued

\begin{tabular}{llrr}
\hline & Graduate Majors of Entrepreneurs & Count & Percent \\
\hline 1 & Computer Science & 636 & $16.38 \%$ \\
2 & Electrical Engineering & 572 & $14.73 \%$ \\
3 & Law & 374 & $9.63 \%$ \\
4 & Medicine & 275 & $7.08 \%$ \\
5 & Business & 180 & $4.64 \%$ \\
6 & Physics & 165 & $4.25 \%$ \\
7 & Engineering & 163 & $4.20 \%$ \\
8 & Chemistry & 155 & $3.99 \%$ \\
9 & Computer Engineering & 116 & $2.99 \%$ \\
10 & Biology & 114 & $2.94 \%$ \\
11 & Mechanical Engineering & 83 & $2.14 \%$ \\
12 & Economics & 63 & $1.62 \%$ \\
13 & Mathematics & 50 & $1.29 \%$ \\
14 & Science & 49 & $1.26 \%$ \\
15 & Chemical Engineering & 38 & $0.98 \%$ \\
16 & Material Science & 36 & $0.93 \%$ \\
17 & Biomedical Engineering & 33 & $0.85 \%$ \\
18 & Education & 30 & $0.77 \%$ \\
19 & Psychology & 30 & $0.77 \%$ \\
20 & Finance & 28 & $0.72 \%$ \\
& & & \\
& Total & 3,883 & $100.00 \%$ \\
\hline & & &
\end{tabular}




\section{Table IX Entrepreneurs Past Employment}

This table summarizes employment history of venture capitalists and entrepreneurs in the sample. The total number of past employers is less than the total number of $\mathrm{VC} /$ entrepreneurs because some people are missing employment history in our data and those are dropped.

\begin{tabular}{|c|c|c|c|c|c|c|c|}
\hline \multicolumn{4}{|c|}{ Entrepreneur (1990 to 2016) } & \multicolumn{4}{|c|}{ VC (1990 to 2016) } \\
\hline & Past Employer & Freq. & Percent & & Past Employer & Freq. & Percent \\
\hline 1 & Microsoft & 557 & $1.56 \%$ & 1 & McKinsey \& Company & 110 & $1.54 \%$ \\
\hline 2 & IBM & 551 & $1.55 \%$ & 2 & Goldman Sachs & 77 & $1.08 \%$ \\
\hline 3 & Sun Microsystems & 348 & $0.98 \%$ & 3 & Morgan Stanley & 50 & $0.70 \%$ \\
\hline 4 & Google & 330 & $0.93 \%$ & 4 & Microsoft & 48 & $0.67 \%$ \\
\hline 5 & Oracle & 295 & $0.83 \%$ & 5 & IBM & 44 & $0.62 \%$ \\
\hline 6 & McKinsey \& Company & 293 & $0.82 \%$ & 6 & Bain \& Company & 40 & $0.56 \%$ \\
\hline 7 & Cisco Systems & 282 & $0.79 \%$ & 7 & Cisco Systems & 35 & $0.49 \%$ \\
\hline 8 & Intel & 251 & $0.70 \%$ & 8 & Merrill Lynch & 35 & $0.49 \%$ \\
\hline 9 & Apple Computer & 244 & $0.69 \%$ & 9 & Boston Consulting Group & 33 & $0.46 \%$ \\
\hline 10 & Hewlett-Packard & 219 & $0.61 \%$ & 10 & Lehman Brothers & 33 & $0.46 \%$ \\
\hline 11 & Yahoo & 195 & $0.55 \%$ & 11 & Ernst \& Young & 26 & $0.36 \%$ \\
\hline 12 & Stanford University & 175 & $0.49 \%$ & 12 & Summit Partners & 24 & $0.34 \%$ \\
\hline 13 & Goldman Sachs & 166 & $0.47 \%$ & 13 & Hewlett-Packard & 23 & $0.32 \%$ \\
\hline 14 & Motorola & 152 & $0.43 \%$ & 14 & Robertson Stephens & 23 & $0.32 \%$ \\
\hline 15 & Accenture & 119 & $0.33 \%$ & 15 & Credit Suisse First Boston & 22 & $0.31 \%$ \\
\hline 16 & Andersen Consulting & 117 & $0.33 \%$ & 16 & Sun Microsystems & 21 & $0.29 \%$ \\
\hline 17 & AT\&T & 104 & $0.29 \%$ & 17 & Google & 21 & $0.29 \%$ \\
\hline 18 & MIT & 103 & $0.29 \%$ & 18 & Deutsche Bank & 20 & $0.28 \%$ \\
\hline 19 & Digital Equipment & 99 & $0.28 \%$ & 19 & Apax Partners & 18 & $0.25 \%$ \\
\hline 20 & Bain \& Company & 95 & $0.27 \%$ & 20 & Accenture & 18 & $0.25 \%$ \\
\hline & Top 20 Total & 4,695 & $13.18 \%$ & & Top 20 Total & 721 & $10.12 \%$ \\
\hline & Sample Total & 35,617 & & & Sample Total & 7,128 & \\
\hline
\end{tabular}




\section{Table X Education (Venture Capitalists)}

This table summarizes education of venture capitalists in the sample. The total number of degrees is less than the total number of VCs because some VCs are missing education history in our sample either due to they did not finish a certain degree or we cannot find it online.

\begin{tabular}{|c|c|c|c|c|c|c|c|}
\hline \multicolumn{4}{|c|}{ College } & \multicolumn{4}{|c|}{ Business School } \\
\hline & & Freq. & Percent & & & Freq. & Percent \\
\hline 1 & Harvard University & 478 & $4.88 \%$ & 1 & Harvard University & 1,192 & $22.04 \%$ \\
\hline 2 & Stanford University & 395 & $4.03 \%$ & 2 & Stanford University & 628 & $11.61 \%$ \\
\hline 3 & University of Pennsylvania & 323 & $3.29 \%$ & 3 & University of Pennsylvania & 508 & $9.39 \%$ \\
\hline 4 & Yale University & 254 & $2.59 \%$ & 4 & Columbia University & 275 & $5.09 \%$ \\
\hline 5 & Princeton University & 250 & $2.55 \%$ & 5 & University of Chicago & 239 & $4.42 \%$ \\
\hline 6 & Dartmouth College & 209 & $2.13 \%$ & 6 & Northwestern University & 209 & $3.86 \%$ \\
\hline 7 & Cornell University & 196 & $2.00 \%$ & 7 & Dartmouth College & 125 & $2.31 \%$ \\
\hline 8 & University of California (Berkeley) & 194 & $1.98 \%$ & 8 & University of California (Los Angeles) & 118 & $2.18 \%$ \\
\hline 9 & Duke University & 164 & $1.67 \%$ & 9 & New York University & 110 & $2.03 \%$ \\
\hline 10 & Massachusetts Institute of Technology & 158 & $1.61 \%$ & 10 & Massachusetts Institute Of Technology & 100 & $1.85 \%$ \\
\hline 11 & University of Virginia & 146 & $1.49 \%$ & 11 & University of Virginia & 90 & $1.66 \%$ \\
\hline 12 & Brown University & 128 & $1.31 \%$ & 12 & University of California (Berkeley) & 85 & $1.57 \%$ \\
\hline 13 & University of Michigan & 115 & $1.17 \%$ & 13 & University of Michigan & 81 & $1.50 \%$ \\
\hline 14 & University of Illinois (Urbana Champaign) & 106 & $1.08 \%$ & 14 & INSEAD & 76 & $1.41 \%$ \\
\hline 15 & Georgetown University & 92 & $0.94 \%$ & 15 & Duke University & 70 & $1.29 \%$ \\
\hline 16 & University of California (Los Angeles) & 86 & $0.88 \%$ & 16 & Yale University & 55 & $1.02 \%$ \\
\hline 17 & Columbia University & 83 & $0.85 \%$ & 17 & Cornell University & 44 & $0.81 \%$ \\
\hline 18 & Tufts University & 83 & $0.85 \%$ & 18 & Indiana University (Bloomington) & 42 & $0.78 \%$ \\
\hline 19 & Williams College & 80 & $0.82 \%$ & 19 & University of North Carolina (Chapel Hill) & 38 & $0.70 \%$ \\
\hline 20 & University Of North Carolina (Chapel Hill) & 69 & $0.70 \%$ & 20 & Boston University & 37 & $0.68 \%$ \\
\hline & Top 20 Total & 3,609 & $36.82 \%$ & & Top 20 Total & 4,122 & $76.22 \%$ \\
\hline & Sample Total & 9,803 & & & Sample Total & 5,408 & \\
\hline
\end{tabular}


Table X. College and Graduate (Venture Capitalists) Continued

\begin{tabular}{rlrr}
\hline \multicolumn{3}{c}{ Graduate School (Non-MBA) } \\
\hline & Stanford University & Freq. & Percent \\
2 & Harvard University & 395 & $9.42 \%$ \\
3 & Massachusetts Institute of Technology & 311 & $7.41 \%$ \\
4 & University of Pennsylvania & 204 & $4.86 \%$ \\
5 & Columbia University & 121 & $2.88 \%$ \\
6 & University of California (Berkeley) & 119 & $2.84 \%$ \\
7 & New York University & 105 & $2.50 \%$ \\
8 & Northwestern University & 82 & $1.95 \%$ \\
9 & Yale University & 82 & $1.95 \%$ \\
10 & Oxford University & 79 & $1.88 \%$ \\
11 & University of Michigan & 73 & $1.74 \%$ \\
12 & Cornell University & 71 & $1.69 \%$ \\
13 & University of Virginia & 68 & $1.62 \%$ \\
14 & University of Chicago & 62 & $1.48 \%$ \\
15 & Cambridge University & 53 & $1.26 \%$ \\
16 & Georgetown University & 48 & $1.14 \%$ \\
17 & University of California (Los Angeles) & 44 & $1.05 \%$ \\
18 & University of Southern California & 42 & $1.00 \%$ \\
19 & Duke University & 41 & $0.98 \%$ \\
20 & Boston University & 36 & $0.86 \%$ \\
& & 35 & $0.83 \%$ \\
& Top 20 Total & & \\
& Sample Total & 2,071 & $49.37 \%$ \\
& & 4,195 & \\
\hline
\end{tabular}




\section{Table XI. College and Graduate Majors (Venture Capitalists)}

This table summarizes degree and majors of venture capitalists in the sample. The total number of degrees is less than the total number of venture capitalists because some venture capitalists are missing education history in our sample either due to they did not finish a certain degree or we cannot find it online.

\begin{tabular}{|c|c|c|c|}
\hline & Undergraduate Majors of VC & Count & Percent \\
\hline 1 & Economics & 634 & $16.72 \%$ \\
\hline 2 & Business & 412 & $10.86 \%$ \\
\hline 3 & Engineering & 379 & $9.99 \%$ \\
\hline 4 & Electrical Engineering & 288 & $7.59 \%$ \\
\hline 5 & Finance & 132 & $3.48 \%$ \\
\hline 6 & Computer Science & 129 & $3.40 \%$ \\
\hline 7 & Accounting & 123 & $3.24 \%$ \\
\hline 8 & Biology & 120 & $3.16 \%$ \\
\hline 9 & Mechanical Engineering & 120 & $3.16 \%$ \\
\hline 10 & History & 114 & $3.01 \%$ \\
\hline 11 & Chemistry & 111 & $2.93 \%$ \\
\hline 12 & Mathematics & 111 & $2.93 \%$ \\
\hline 13 & Science & 93 & $2.45 \%$ \\
\hline 14 & Political Science & 90 & $2.37 \%$ \\
\hline 15 & Physics & 72 & $1.90 \%$ \\
\hline 16 & Social Studies & 51 & $1.34 \%$ \\
\hline 17 & English & 49 & $1.29 \%$ \\
\hline 18 & Chemical Engineering & 47 & $1.24 \%$ \\
\hline 19 & Industrial Engineering & 45 & $1.19 \%$ \\
\hline \multirow[t]{2}{*}{20} & Law & 45 & $1.19 \%$ \\
\hline & Total & 3,793 & $100.00 \%$ \\
\hline
\end{tabular}


Table XI. College and Graduate Majors (Venture Capitalists) Continued

\begin{tabular}{llrr}
\hline & Graduate Degrees of VC & Count & Percent \\
\hline 1 & Master (Non MBA) & 1,278 & $54.11 \%$ \\
2 & JD & 462 & $19.56 \%$ \\
3 & PhD & 438 & $18.54 \%$ \\
4 & MD & 179 & $7.58 \%$ \\
& & & \\
& Total (Non MBA) & 2,362 & $100.00 \%$ \\
\hline \multicolumn{2}{r}{ Note: 5,408 out of 9,803 Venture Capitalists have an MBA degree. }
\end{tabular}

\begin{tabular}{llrr}
\hline & Graduate Majors of VCs (Non MBA) & Count & Percent \\
\hline 1 & Law & 467 & $33.94 \%$ \\
2 & Medicine & 188 & $13.66 \%$ \\
3 & Science & 146 & $10.61 \%$ \\
4 & Electrical Engineering & 106 & $7.70 \%$ \\
5 & Business & 51 & $3.71 \%$ \\
6 & Chemistry & 43 & $3.13 \%$ \\
7 & Engineering & 43 & $3.13 \%$ \\
8 & Computer Science & 38 & $2.76 \%$ \\
9 & Biology & 32 & $2.33 \%$ \\
10 & Economics & 27 & $1.96 \%$ \\
11 & Physics & 24 & $1.74 \%$ \\
12 & Chemical Engineering & 22 & $1.60 \%$ \\
13 & Public Administration & 18 & $1.31 \%$ \\
14 & Mechanical Engineering & 17 & $1.24 \%$ \\
15 & Finance & 15 & $1.09 \%$ \\
16 & Industrial Engineering & 12 & $0.87 \%$ \\
17 & International Relations & 12 & $0.87 \%$ \\
18 & Accounting & 11 & $0.80 \%$ \\
19 & Pharmacology & 11 & $0.80 \%$ \\
20 & Mathematics & 28 & $0.72 \%$ \\
& & & \\
& Total & 1,376 & $100.00 \%$ \\
\hline
\end{tabular}




\section{Table XII Venture Capitalist Past Employment}

This table summarizes employment history of venture capitalists in the sample. The total number of past employers is less than the total number of $\mathrm{VC} /$ entrepreneurs because some people are missing employment history in our data and those are dropped.

\begin{tabular}{rlrr}
\hline \multicolumn{3}{c}{ VC (1990 to 2016) } \\
\hline & Past Employer & Freq. & Percent \\
2 & McKinsey \& Company & 110 & $1.54 \%$ \\
3 & Goldman Sachs & 77 & $1.08 \%$ \\
4 & Microsoft & 50 & $0.70 \%$ \\
5 & IBM & 48 & $0.67 \%$ \\
6 & Bain \& Company & 44 & $0.62 \%$ \\
7 & Cisco Systems & 40 & $0.56 \%$ \\
8 & Merrill Lynch & 35 & $0.49 \%$ \\
9 & Boston Consulting Group & 35 & $0.49 \%$ \\
10 & Lehman Brothers & 33 & $0.46 \%$ \\
11 & Ernst \& Young & 33 & $0.46 \%$ \\
12 & Summit Partners & 26 & $0.36 \%$ \\
13 & Hewlett-Packard & 24 & $0.34 \%$ \\
14 & Robertson Stephens & 23 & $0.32 \%$ \\
15 & Credit Suisse First Boston & 23 & $0.32 \%$ \\
16 & Sun Microsystems & 22 & $0.31 \%$ \\
17 & Google & 21 & $0.29 \%$ \\
18 & Deutsche Bank & 21 & $0.29 \%$ \\
19 & Apax Partners & 20 & $0.28 \%$ \\
20 & Accenture & 18 & $0.25 \%$ \\
& & 18 & $0.25 \%$ \\
& Top 20 Total & & \\
& Sample Total & 721 & $10.12 \%$ \\
\hline & & & \\
\hline
\end{tabular}


Table XIII. Female/Minority Ratio by State

This table sort states by fraction of female, underrepresented minority and Asian Entrepreneurs and VCs. It only includes states with more than 100 entrepreneurs or more than $50 \mathrm{VCs}$.

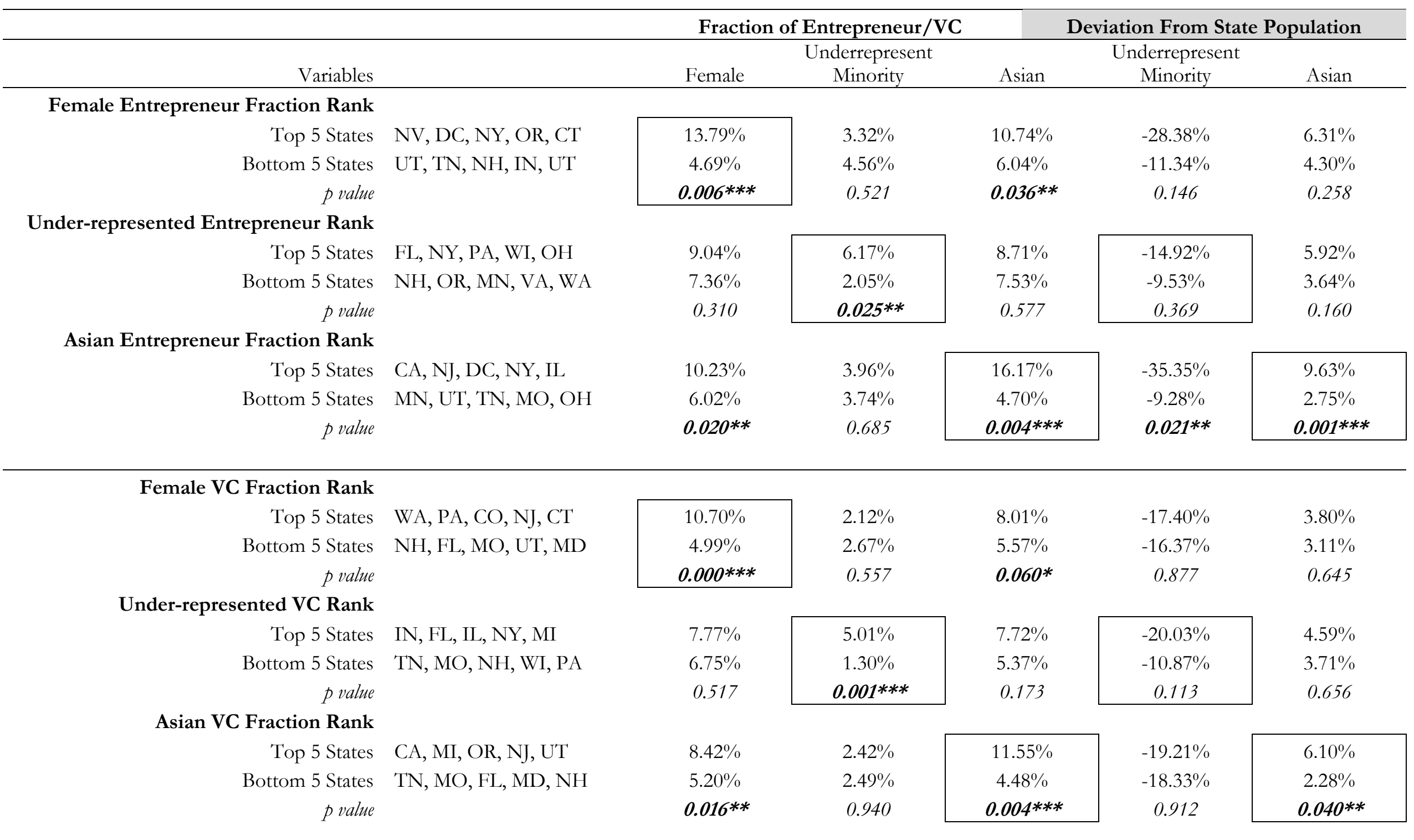


Table XIV. Sort by State Characteristics

This table sort female, underrepresented minority and Asian by state characteristics. It only includes states with more than 100 Entrepreneurs and 50 VCs.

\begin{tabular}{|c|c|c|c|c|c|c|c|c|}
\hline & \multicolumn{2}{|l|}{ State Characteristics } & \multicolumn{3}{|c|}{ Entrepreneur } & \multicolumn{3}{|c|}{ VC } \\
\hline & & & & Under & & & Under & \\
\hline & Political view: Percentage of republican & \% Republican & Female & Represented & Asian & Female & represented & Asian \\
\hline Top 5 States & UT, PA, GA, TN, AZ & $31.60 \%$ & $6.30 \%$ & $4.28 \%$ & $8.22 \%$ & $7.06 \%$ & $1.85 \%$ & $7.28 \%$ \\
\hline Bottom 5 States & MA, CT, MD, NY, CA & $20.00 \%$ & $9.45 \%$ & $4.29 \%$ & $13.64 \%$ & $8.51 \%$ & $2.94 \%$ & $9.04 \%$ \\
\hline \multirow[t]{2}{*}{$p$ value } & & 0.002 & $0.058 *$ & 0.977 & $0.087 *$ & 0.269 & $0.063 *$ & 0.441 \\
\hline & Union: Percentage of Union Members & $\%$ Union & & & & & & \\
\hline Top 5 States & NY, MI, NJ, WA, IL & $21.19 \%$ & $9.53 \%$ & $3.57 \%$ & $12.92 \%$ & $9.43 \%$ & $3.52 \%$ & $8.32 \%$ \\
\hline Bottom 5 States & NC, GA, TX, VA, FL & $5.73 \%$ & $6.64 \%$ & $4.84 \%$ & $9.78 \%$ & $6.79 \%$ & $3.41 \%$ & $6.60 \%$ \\
\hline \multirow[t]{2}{*}{ pvalue } & & 0.000 & $0.029 * *$ & 0.476 & 0.131 & $0.049 * *$ & 0.903 & 0.206 \\
\hline & Religion: Percentage of Christian & $\%$ Christian & & & & & & \\
\hline Top 5 States & TN, TX, NC, GA, PA & $83.00 \%$ & $6.93 \%$ & $3.90 \%$ & $9.31 \%$ & $7.92 \%$ & $2.09 \%$ & $6.77 \%$ \\
\hline Bottom 5 States & OR, WA, NH, CO, CA & $69.80 \%$ & $8.12 \%$ & $2.56 \%$ & $10.14 \%$ & $8.57 \%$ & $2.10 \%$ & $9.58 \%$ \\
\hline \multirow[t]{2}{*}{ pvalue } & & 0.000 & 0.376 & $0.096 *$ & 0.818 & 0.697 & 0.996 & 0.236 \\
\hline & Economy: GDP per capita & GDP per capita & & & & & & \\
\hline Top 5 States & CT, MA, NY, NJ, WA & 55913.5 & $9.47 \%$ & $3.89 \%$ & $12.62 \%$ & $10.02 \%$ & $2.63 \%$ & $7.98 \%$ \\
\hline Bottom 5 States & FL,AZ,TN, UT, MI & 40285.58 & $6.48 \%$ & $5.22 \%$ & $7.42 \%$ & $6.39 \%$ & $2.82 \%$ & $7.54 \%$ \\
\hline \multirow[t]{2}{*}{ pvalue } & & 0.001 & $0.098 *$ & 0.427 & $0.043 * *$ & $0.008^{* * *}$ & 0.850 & 0.791 \\
\hline & Improvement in Education & $\begin{array}{c}\text { Education } \\
\text { Change }\end{array}$ & & & & & & \\
\hline Top 5 States & $\mathrm{MA}, \mathrm{NJ}, \mathrm{MD}, \mathrm{CT}, \mathrm{NH}$ & $11.38 \%$ & $7.77 \%$ & $3.32 \%$ & $11.78 \%$ & $7.85 \%$ & $2.19 \%$ & $7.15 \%$ \\
\hline Bottom 5 States & AZ, UT, TX, CA, TN & $6.52 \%$ & $6.13 \%$ & $3.97 \%$ & $10.54 \%$ & $6.60 \%$ & $2.24 \%$ & $9.05 \%$ \\
\hline \multirow[t]{2}{*}{ pvalue } & & 0.000 & 0.281 & 0.316 & 0.754 & 0.407 & 0.936 & 0.427 \\
\hline & Maternal/family Leave Benefit & Benefit Score & & & & & & \\
\hline Top 5 States & CA, OR, NJ, CT, WA & 87 & $9.32 \%$ & $3.20 \%$ & $13.27 \%$ & $9.67 \%$ & $2.34 \%$ & $10.31 \%$ \\
\hline Bottom States & MD, VA,GA,NC, PA, MO, TX & 0 & $7.30 \%$ & $3.75 \%$ & $10.02 \%$ & $7.29 \%$ & $2.43 \%$ & $6.58 \%$ \\
\hline p value & & 0.001 & $0.059 *$ & 0.395 & 0.375 & 0.164 & 0.845 & $0.089 *$ \\
\hline
\end{tabular}

Source: (1) Republican Ratio, Christian population are retrieved from Gallup 2010 Party Affiliation. (2) union data is retrieved from http://www.unionstats.com/ by Barry T. Hirsch and David A. Macpherson,

"Union Membership and Coverage Database from the Current Population Survey: Note," Industrial and Labor Relations Review, Vol. 56, No. 2, January 2003, pp. 349-54. The union membership data used in this table is the average of 1990, 2000 and 2010. (3) GDP Data retrieved from Bureau of Economic Analysis. It is the average of 1997-2010, in 2009 dollars. (4) Education data is retrieved from Census Bureau, 1970, 1980, 1990, 2000 Censuses of Population, and the 2010-2014 American Community Surveys. (5) Benefit score is retrieved from National Partnership for Women \& Families (2005). Expecting Better: A

State-by-State Analysis of Laws That Help New Parents. https://www.lidac.com/pdf/ParentalLeaveReportMay05.pdf 
Table XV. Diversity and State Characteristics Univariate Regression

This table reports univariate regression coefficient of state characteristics on Female Ratio and Minority Ratio. The dependent variables (first column) are female (or minority) ratios in venture capital and entrepreneurship. The independent variable for each univariate regression is state level republican ratio, union member ratio, Christian ratio, log GDP per Capita, Maternity Benefit Score and College Graduation rate growth. Asterisks denote statistical significance at the 1\% (***), 5\% (**), or $10 \%(*)$ level.

\begin{tabular}{|c|c|c|c|c|c|c|c|}
\hline & Republican & $\begin{array}{l}\text { Union } \\
\text { Member }\end{array}$ & Christian & $\begin{array}{c}\text { Log GDP } \\
\text { per cap }\end{array}$ & $\begin{array}{c}\text { Maternity } \\
\text { benefit }\end{array}$ & $\begin{array}{l}\text { College } \\
\text { graduate } \\
\text { growth }\end{array}$ & Obs \\
\hline Female Entrepreneur Ratio & $\begin{array}{c}-0.258 * * * \\
(0.0559)\end{array}$ & $\begin{array}{c}0.264 * * * \\
(0.0607)\end{array}$ & $\begin{array}{c}-0.283 * * * \\
(0.0803)\end{array}$ & $\begin{array}{c}0.0534 * * * \\
(0.0120)\end{array}$ & $\begin{array}{c}0.000165 \\
(0.000172)\end{array}$ & $\begin{array}{l}-0.244 \\
(0.535)\end{array}$ & 28 \\
\hline Female VC Ratio & $\begin{array}{l}-0.142 * * \\
(0.0620)\end{array}$ & $\begin{array}{c}0.180 * * * \\
(0.0590)\end{array}$ & $\begin{array}{c}-0.122 \\
(0.0833)\end{array}$ & $\begin{array}{c}0.0831 * * * \\
(0.0220)\end{array}$ & $\begin{array}{c}0.000235 * * \\
(0.000102)\end{array}$ & $\begin{array}{c}0.311 \\
(0.182)\end{array}$ & 26 \\
\hline Under-represented Entrepreneur Ratio & $\begin{array}{c}0.0412 \\
(0.0277)\end{array}$ & $\begin{array}{l}-0.0335 \\
(0.0686)\end{array}$ & $\begin{array}{l}0.0859 * \\
(0.0432)\end{array}$ & $\begin{array}{l}-0.00942 \\
(0.00913)\end{array}$ & $\begin{array}{l}-8.38 \mathrm{e}-05 \\
(7.87 \mathrm{e}-05)\end{array}$ & $\begin{array}{l}-0.106 \\
(0.120)\end{array}$ & 28 \\
\hline Under-represented Minority VC Ratio & $\begin{array}{l}-0.0169 \\
(0.0472)\end{array}$ & $\begin{array}{c}0.0296 \\
(0.0437)\end{array}$ & $\begin{array}{c}0.0154 \\
(0.0476)\end{array}$ & $\begin{array}{l}0.00424 \\
(0.0223)\end{array}$ & $\begin{array}{l}-6.94 \mathrm{e}-05 \\
(5.83 \mathrm{e}-05)\end{array}$ & $\begin{array}{c}-0.0849 \\
(0.128)\end{array}$ & 26 \\
\hline Asian Entrepreneur Ratio & $\begin{array}{c}-0.330 * * * \\
(0.0793)\end{array}$ & $\begin{array}{l}0.211 * \\
(0.116)\end{array}$ & $\begin{array}{l}-0.247 \\
(0.151)\end{array}$ & $\begin{array}{c}0.0684 * * \\
(0.0256)\end{array}$ & $\begin{array}{c}0.000513 \\
(0.000314)\end{array}$ & $\begin{array}{c}0.487 \\
(0.393)\end{array}$ & 28 \\
\hline Asian VC Ratio & $\begin{array}{r}-0.0717 \\
(0.104) \\
\end{array}$ & $\begin{array}{c}0.135 * \\
(0.0715) \\
\end{array}$ & $\begin{array}{c}-0.230 * * \\
(0.102)\end{array}$ & $\begin{array}{r}0.0264 \\
(0.0367) \\
\end{array}$ & $\begin{array}{c}0.000424 * * \\
(0.000185) \\
\end{array}$ & $\begin{array}{l}-0.249 \\
(0.270) \\
\end{array}$ & 26 \\
\hline
\end{tabular}

